\title{
Fretting Wear and Scratch Resistance of Cold-Sprayed Pure Cu and Ti
}

\author{
Rodolpho F. Váz ${ }^{1}$ Alessio Silvello ${ }^{1}$ - Pasquale D. Cavalière ${ }^{2}$ (D) Sergi Dosta ${ }^{1} \cdot$ Irene G. Cano $^{1} \cdot$ Laura Capodieci $^{3}$. \\ Antonella Rizzo ${ }^{3} \cdot$ Daniele Valerini $^{3}$
}

Received: 18 May 2021 / Revised: 30 June 2021 / Accepted: 2 July 2021 / Published online: 20 July 2021

(C) The Author(s) 2021, corrected publication 2021

\begin{abstract}
The paper analyses the fretting and wear behavior of pure copper and pure titanium coatings realized through cold spray. The coatings were designed and produced by employing processing conditions leading to minimum porosity and high hardness; these conditions were $700{ }^{\circ} \mathrm{C}$ and 40 bar for Ti powders and $400{ }^{\circ} \mathrm{C}$ and 30 bar for $\mathrm{Cu}$ ones. The low porosity and high strength materials led to high resistance to wear damaging through the optimal energy dissipation upon fretting. Due to the sprayed particles deformation mode, the sprayed materials show non-uniform hardening along the deposition distance. As a matter of fact, hardness varied in the range 3.7-4.2 GPa for Ti coatings and 1.5-2 GPa for the $\mathrm{Cu}$ ones depending on the distance from the substrate and on the coatings thickness. This influenced the materials properties and the response to the wear damaging. This was demonstrated by the scratch tests performed on coatings with different thicknesses. Those coatings sprayed in major thickness revealed the best wear resistance due to the deformation hardening. The harder coatings also revealed brittle fracture at the experienced highest loads.
\end{abstract}

Keywords Cold spray $\cdot$ Mechanical properties $\cdot$ Hardening $\cdot$ Wear damage $\cdot$ Fretting damage

\section{Introduction}

Cold spray is recognized as an optimal additive manufacturing (AM) technology capable of producing sound bulk components [1-4] with exceptional performances experienced by copper-, nickel- and titanium-based materials [5-9]. During cold spray process, a high pressurized gas is employed to accelerate metallic particles at temperatures well below their melting points. The sprayed particles severely deform upon impacting on hard substrates leading to compact deposits. This low-temperature thermal spray technology avoids undesirable oxidation processes or phase modifications in the sprayed materials leading to the obtaining of components characterized by good mechanical properties [10].

Pasquale D. Cavalière

pasquale.cavaliere@unisalento.it

1 Thermal Spray Center CPT, Universitat de Barcelona, Barcelona, Spain

2 Department of Innovation Engineering, University of Salento, Lecce, Italy

3 ENEA - Italian National Agency for New Technologies, Energy and Sustainable Economic Development, Brindisi, Italy
The sprayed particles exhibit severe plastic deformation upon impacting; this induces many microstructural modifications that are responsible for the bonding to the substrate and among the different particles [11]. The activated microstructural features are dependent on the sprayed particles properties, the substrate surface and mechanical properties and the employed pressure and temperature of the spray gases. As these properties are varied, different coatings behaviors are expected [12]. In particular, the coatings properties are very sensitive to the selected spray parameters $[13,14]$. Many scientific evidences underline that the particle-particle cohesion is due to the achievement of the adiabatic shear instability. This phenomenon leads to local temperature increase supporting the particle deformation that behaves as a viscous material. This allows for the oxides rupture with consequent optimal adhesion and particles interlocking $[15,16]$. Other scientific evidences underline that peripheral jets form as a consequence of strong pressure waves due to impact leading to the expansion of the particle edge [17]. By considering the sprayed pure metals behavior, the processing conditions variation largely affects the deformation mechanisms and the consequent mechanical and microstructural properties [18-20]. In general, processing conditions influence the severe plastic deformation levels; this governs the 
metallurgical bonding and is revealed by the flattening ratio of the particles after impact. The measurement of the flattening ratio allows for the determination of the deformation behavior of the material at different distances for the surface toward the substrate $[21,22]$.

Titanium and its alloys show well-known microstructural and mechanical properties [23] allowing them to be applied in many civil and industrial applications from aerospace $[24,25]$ to biomedical [26] to protective components [27]. Copper and its alloys are mainly employed in those fields requiring materials with high electrical and thermal properties [28-31].

Ti coatings have been produced in order to increase the resistance to fretting and wear of aluminum and aluminum alloys [32]. Fretting wear evolves through various phenomena due to the continuous contact between two surfaces; the developed microstructural mechanisms lead to fatigue cracking and delamination of the superficial layers. Once continue sliding acts, microcracks nucleate and continue to grow up to fatigue damaging and macroscopic fracture [33]. In general, the fretting behavior of materials involves various microstructural features that continuously interact and overlap during continuous loading [34]. The fretting wear and scratch behavior of cold spray coatings is not so presented in literature [35]. It is well known that material porosity and hardness/elastic modulus are the main factors affecting the wear behavior [36].

In the classical approach, only hardness is considered as the principal aspect governing the wear response of surfaces. As the material hardens, also the elastic modulus starts to play a fundamental role. So, not the hardness and elastic modulus must be taken into consideration to completely characterize such fundamental material behavior. In this direction, the hardness to elastic modulus ratio provides many information about the surface mechanisms acting during sliding. Nanoindentation is a well-established technique developed to precisely measure the local hardness and elastic moduli of bulk materials and coatings [37]. Nano-probe techniques allow for the continuous characterization of mechanical properties as well as the surface ones under contact loading. Anyway, the relationships between local mechanical properties and the wear response are not conclusive. This is complicated in those conditions where complex triaxial stresses act on small volumes [38].

Very few experimental evidences are presented on the scratch response of cold spray deposits [39, 40]. Here, nanoindentation and scratch are employed to continuously characterize the coatings mechanical properties along the deposition path. The analyses of scratch tracks allowed to identify the surface damage consequent to sliding at different load levels. The results are very useful for cold spray design in order to optimize the coatings microstructure, mechanical properties and dimensions.

\section{Experimental Procedure}

\section{Materials}

Pure copper powders with particle distribution $+18-41$ $\mu \mathrm{m}$ and mean dimensions of $27 \pm 1.5 \mu \mathrm{m}$ were provided by Safina (Ploiesti, Romania); pure titanium powders with particle distribution $+15-44 \mu \mathrm{m}$ and mean dimensions of $30 \pm 2 \mu \mathrm{m}$ were provided by AP\&C (Boisbriand, QC, Canada). Granulometry was measured through laser scattering by employing Beckman Coulter LS 13320 (Brea, CA, USA). Phase analysis was evaluated through XRD Malvern PANalytical X'Pert PRO MPD $\theta / \theta$ Bragg-Brentano powder diffractometer (Malvern, United Kingdom), with font of $\mathrm{Cu} \mathrm{K} \alpha(\lambda=1.5418 \AA)$ and work power 45 $\mathrm{kV}-40 \mathrm{~mA}$ was used. Scanning electron microscopy (SEM), Thermo Fisher Phenom Pro Desktop SEM (Eindhoven, Netherlands), was employed for microstructural characterization.

The particle dimensions distributions are shown in Fig. 1. The particles are spherical shaped as shown in Fig. 2. The carbon steel substrate was alumina sandblasted before spraying.

The X-ray spectra of the employed particles are plotted in Fig. 3.

\section{Coatings Deposition}

The coatings were produced with a CGT Kinetics 4000 (Haun, Germany) with a SiC nozzle. It has a rectangular cross section measuring $2 \times 4 \mathrm{~mm}$ throat and $2 \times 10 \mathrm{~mm}$ exit at CPT facilities (Barcelona, Spain). The employed substrate was a C20 carbon steel. The selected cold spray parameters are shown in

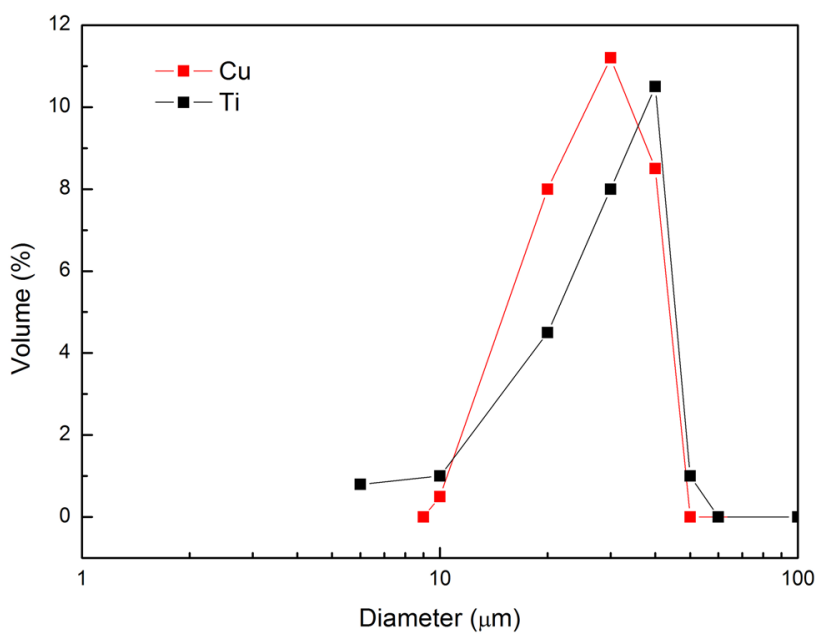

Fig. 1 Particle diameter distribution of the employed powders 

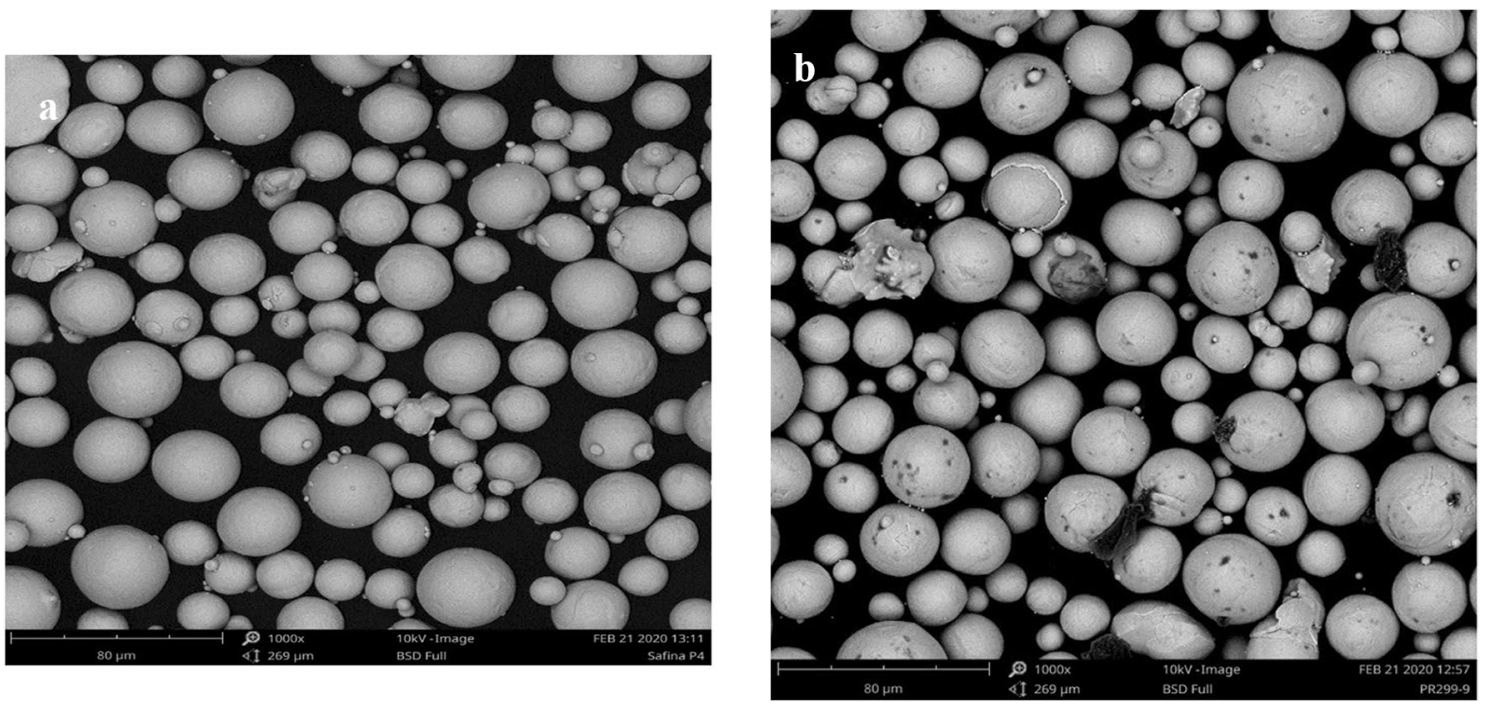

Fig. 2 Powders aspect (a) $\mathrm{Cu}$ and (b) $\mathrm{Ti}$

Fig. 3 X-ray analyses results of the studied particles

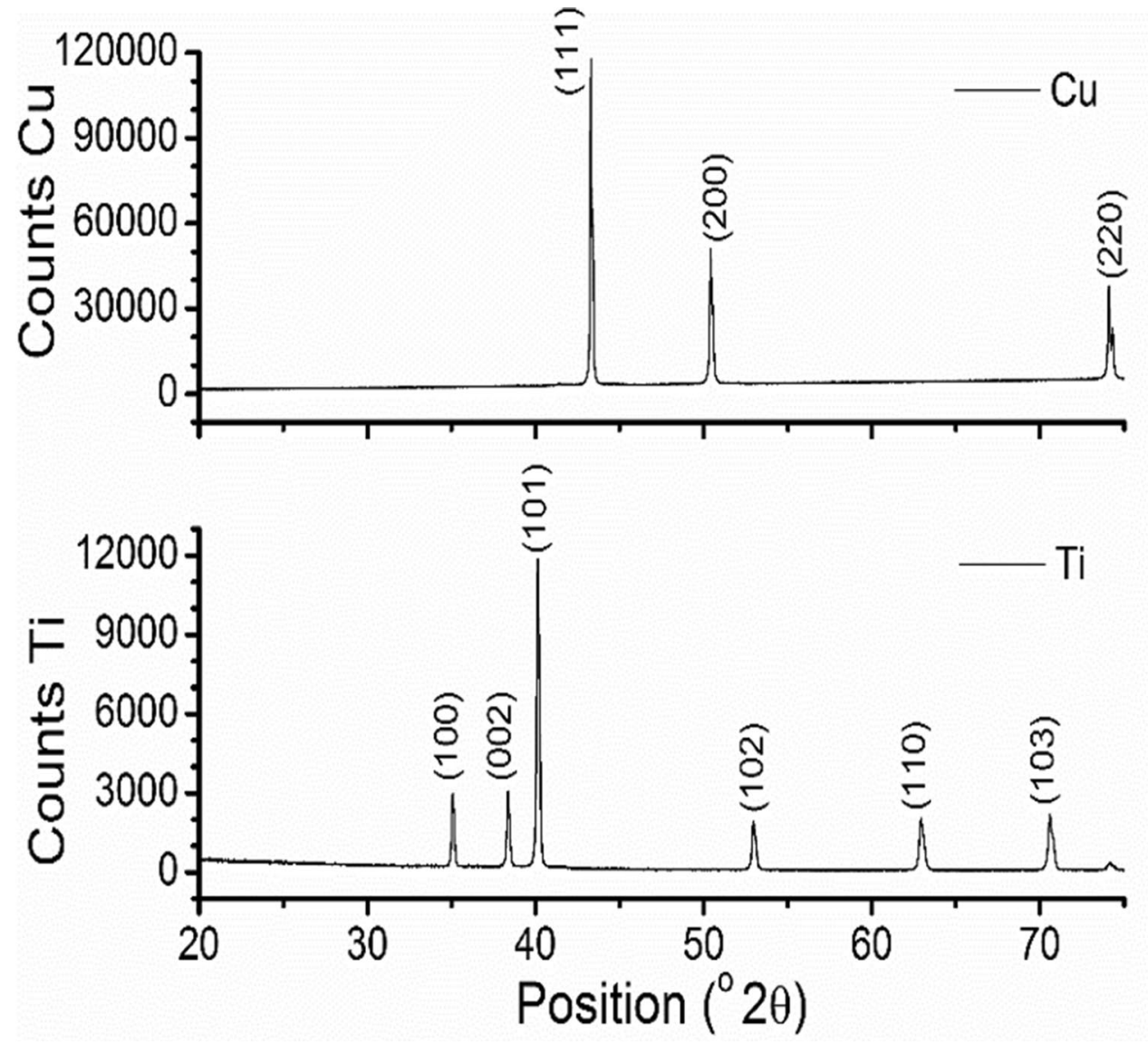

Table 1 Cold spray parameters

\begin{tabular}{lllllll}
\hline Material & $\begin{array}{l}\mathrm{N}_{2} \text { tempera- } \\
\text { ture, }{ }^{\circ} \mathrm{C}\end{array}$ & $\begin{array}{l}\mathrm{N}_{2} \text { pressure, } \\
\text { bar }\end{array}$ & $\begin{array}{l}\text { Standoff dis- } \\
\text { tance, } \mathrm{mm}\end{array}$ & $\begin{array}{l}\text { Powder feed, } \\
\mathrm{rpm}\end{array}$ & $\begin{array}{l}\text { Robot speed, } \\
\mathrm{m} \mathrm{s}^{-1}\end{array}$ & Step, mm \\
\hline $\mathrm{Ti}$ & 700 & 40 & 40 & 3 & 0.50 & 1 \\
$\mathrm{Cu}$ & 400 & 30 & 40 & 2 & 0.50 & 1 \\
\hline
\end{tabular}




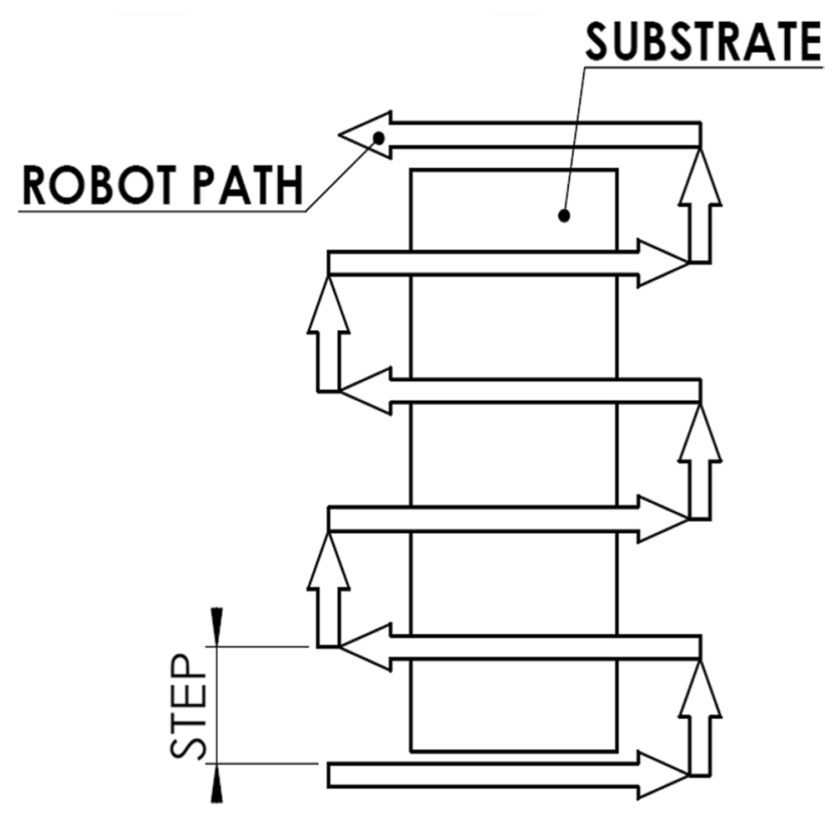

Fig. 4 Robot path employed for cold spray deposition

Table 1. The deposition procedure is show in Fig. 4. The $\mathrm{Cu}$ coatings measured 0.1 and $1 \mathrm{~mm}$ in thicknesses, after 1 and 10 passes, respectively, Ti coatings measured 0.2 and $1 \mathrm{~mm}$ thicknesses, after 1 and 5 passes, respectively.

\section{Coatings Characterizations}

Metallographic preparation was performed according to the ASTM E192. Samples were grinded and polished. Leica DMI5000M (Wetzlar, Germany) microscope was employed for optical microscopy observations. The coatings thickness was measured by employing the Leica picture analyzer. The porosity levels and distribution were calculated by using the Image J processing software.

The coating mechanical properties were evaluated by employing an Anton Paar nanoindentation equipment model TTX-NHT2 (Ostfildern, Germany), with a Berkovich diamond indenter. The tests were developed in load control mode, the loading and unloading rates were $20 \mathrm{mN} / \mathrm{min}$, and the fixed dwell time was $5 \mathrm{~s}$. The coatings mechanical properties were obtained through the Oliver and Pharr methods from the load-depth indentations curves.

ASTM C633 standard was employed for adhesion properties characterization of the coatings. Steel cylinders' top surfaces were sprayed with $\mathrm{Cu}$ and Ti powders in the previous described conditions. Then, they were glued to the respective counter-bodies of the same size. The employed glue was a FM-1000-FOOT elastometric wafer (Indestructible Paint Inc.). The adhesive strength of the glue was measured resulting $70 \mathrm{MPa}$. Tensile tests were then performed on these cylinders in order to measure the adhesive strength. Seven tests per condition were performed.

Scratch tests were performed by using an Anton Paar Revetest instrument (Ostfildern, Germany) with a Rockwell$\mathrm{C}$ diamond indenter. The normal load was linearly varied from 1 to $200 \mathrm{~N}$. The total scratch length was $10 \mathrm{~mm}$. The scratching speed was $10 \mathrm{~mm} / \mathrm{min}$. The fretting wear behavior was analyzed by employing a Nanovea Tribometer T500 (Irvine, CA, USA).

Friction is measured thanks to a load cell mounted on the arm. An image processing system mounted on an optical microscope allows to analyze the traces of wear. A profilometer is employed for measuring the tracks traces. From the profilometer analyses, the wear volume loss is then calculated. The test was performed in dry mode by using a tungsten carbide pin.

\section{Results and Discussions}

The morphologies of the coatings cross section obtained by optical microscopy are shown in Fig. 5. The porosity of the $\mathrm{Cu}$ coatings was $0.15 \pm 0.05 \%$ and $0.25 \pm 0.07 \%$, for 0.2 $\mathrm{mm}$ and $1.0 \mathrm{~mm}$, respectively, while the porosity of the $\mathrm{Ti}$ coatings was $1.72 \pm 0.10 \%$ and $1.81 \pm 0.08 \%$, for $0.1 \mathrm{~mm}$ and $1.0 \mathrm{~mm}$, respectively. The porosity evaluation is fundamental because it strongly influences both the coating adhesion and the overall mechanical behavior.

The porosity of $\mathrm{Cu}$ coatings was lower than the values presented by Yin et al. [7] and Huang et al. [28], who obtained the best value of $1.67 \pm 0.21 \%$ and $0.8 \pm 0.4 \%$, even with higher temperature, 650 and $800{ }^{\circ} \mathrm{C}$, respectively, than the used in this work. The porosity of Ti coatings reached very low levels [25, 41], $1.8 \pm 0.08 \%$ and $1.0 \%$, respectively. As the impact velocity increases, the particles flatten more severely; this is favored by increases in gas temperature and pressure. By tuning an ideal impact velocity, a very high particles flattening is obtained and a reduction of the deposit porosity can be recorded. This is accompanied with the particle-particle voids filling as the severe plastic deformation increases [42]. Metallurgical bonding is favored by the increases in impact energy as a consequence of the increases in severe plastic deformation [18]. The deformation level is evaluated through the single particle splatting that leads to the transformation from the spherical shape to the pancake-like one. With low impact energy, particles retain their spherical shape and the particle-particle voids are not filled sufficiently. Now, the main factors influencing the energy at impact are the particles velocity and the impact temperature; the particles energy upon impact is intrinsically related to the particle velocity at the same temperature; as a 

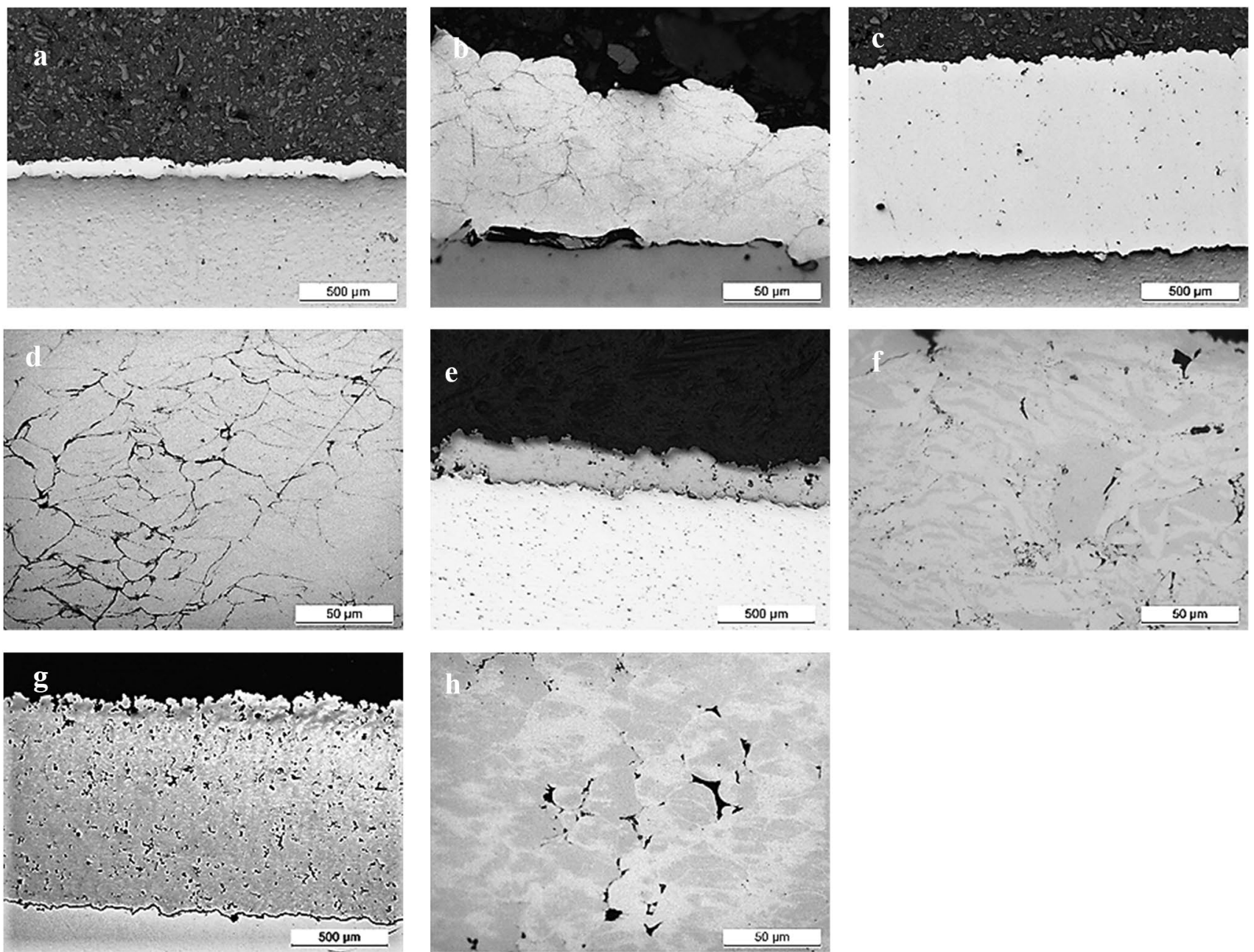

Fig. 5 Images of coatings. (a, b) Cu $0.1 \mathrm{~mm},(\mathbf{c}, \mathbf{d}) \mathrm{Cu} 1.0 \mathrm{~mm},(\mathbf{e}, \mathbf{f}) \mathrm{Ti} 0.2 \mathrm{~mm}$, and (g, h) Ti $1.0 \mathrm{~mm}$

consequence, porosity shows a dependence on the temperature at impact with an exponential behavior [43].

Figure 5d shows how particles strongly deform by impacting on the substrate; their shape becomes elliptical. This is very different from the Ti powders, Fig. 5h, where the particles deformation is less pronounced. The microhardness of the coatings was $100 \pm 11 \mathrm{HV}_{0.2} 123 \pm 8 \mathrm{HV}_{0.2}$, for $\mathrm{Cu} 0.1$ $\mathrm{mm}$ and $1.0 \mathrm{~mm}$, respectively, and $224 \pm 9 \mathrm{HV}_{0.2}, 209 \pm 23$ $\mathrm{HV}_{0.2}$, for Ti $0.2 \mathrm{~mm}$ and $1.0 \mathrm{~mm}$, respectively.

As largely described in the introduction, it is believed that deep analyses of surface response to complex loading require the precise probing of both hardness and elastic modulus in all the coatings volume [44]. Initially, nanoindentations were performed on the polished surface of the spayed copper and titanium. The results for all the sprayed thicknesses are shown in Fig. 6.

In the first stage of indentation, the deformation is pure elastic for very low loads levels. By increasing the indentation force, the curve does not show the classical Hertian trend. This is due to the fact that shear deformation accumulates in the tip region with consequent plastic deformation behavior. This is due to the dislocations accumulation in the strained region; this accumulation is governed by dislocation pile-up that increases as the plastic strain continues. The indentations track on the $\mathrm{Cu}$ coatings surfaces is illustrated in Fig. 7a and b. The typical copper ductility is revealed by the intense plastically deformed region around the track. This behavior appears very limited for the titanium coatings, this was due to the higher stiffness of this material if compared with the copper one, and this can be clearly viewed from the indentations tracks in Fig. 7c and d.

For all the sprayed coatings, hardness decreases from the substrate toward the surface (Fig. 8).

This behavior is attributed to the continuous deformation experienced by the coating as a consequence of the progression of impact; in fact, the material continues to develop hardening as a consequence of particles impacting on the previously sprayed material up to the end of the coating 

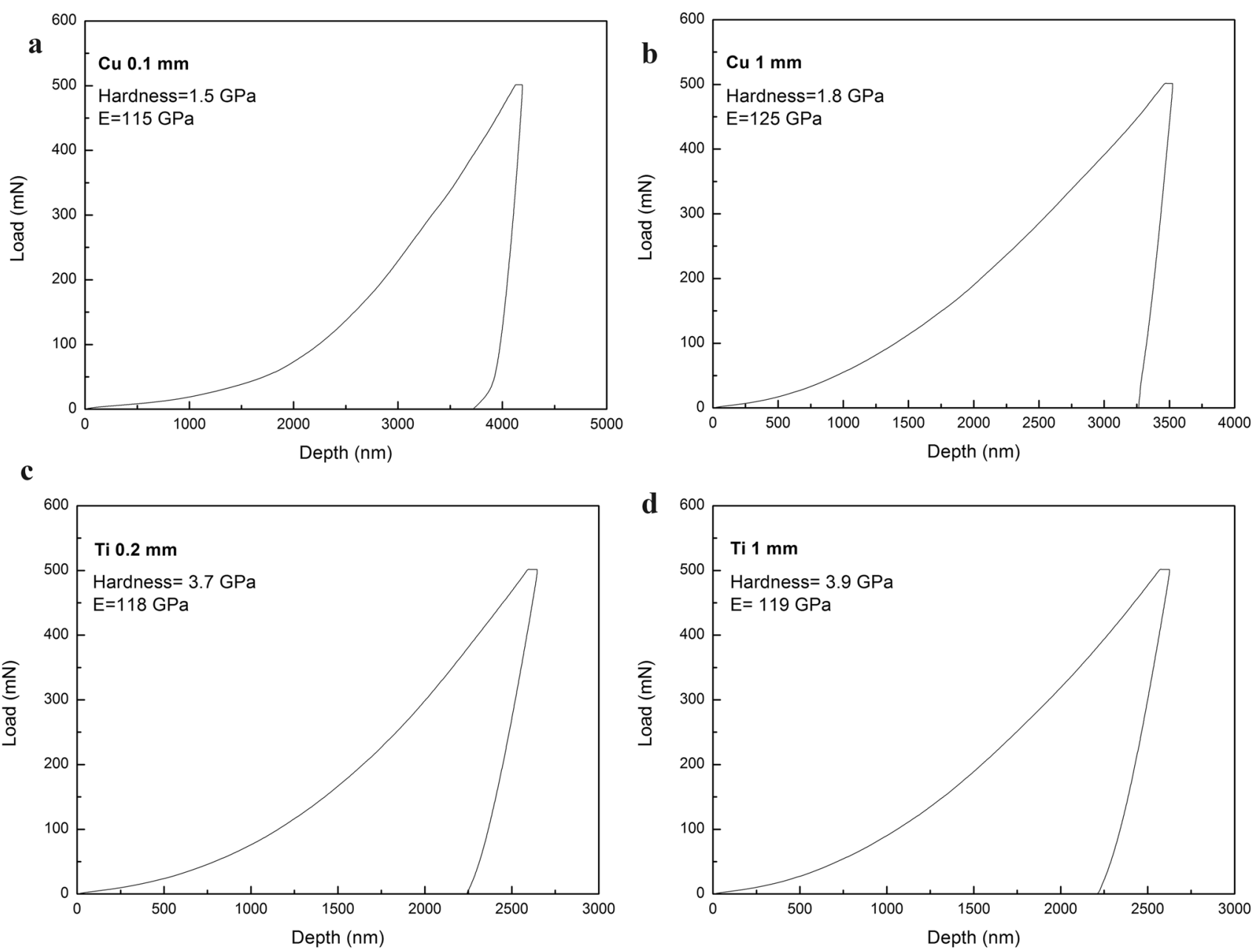

Fig. 6 Nanoindentation curves. (a) $\mathrm{Cu} 0.1 \mathrm{~mm}$, (b) $\mathrm{Cu} 1.0 \mathrm{~mm}$, (c) Ti $0.2 \mathrm{~mm}$, and (d) Ti $1.0 \mathrm{~mm}$ coatings

deposition. The first deposited particles adhere to the substrate in the first stages of the cold spray process. The further sprayed particles splat by deforming on the previously sprayed material by contributing to the global severe plastic deformation of the coating. In addition, voids are filled as the process continues to evolve. This void filling as well as the continuous plastic deformation contributes to the hardness increase. Obviously this increase is more pronounced as the material is closer to the substrate.

The samples aspect after adhesion tests is shown in Fig. 9.

The measured adhesion strength was $48 \pm 4 \mathrm{MPa}$ for copper coatings and $61 \pm 5 \mathrm{MPa}$ for titanium coatings. The aspect of the coating materials after tests revealed decohesion among the particles with local plasticity behavior around each particle. This local plastic deformation resulted more pronounced in the case of copper coatings with respect to the titanium ones (Fig. 10).

It can be stated that the failure mode was mainly cohesive. This behavior is related to the energy that is dissipated along with the propagation of cracks' delamination. This is related to the interface energy at the coating-substrate interface and then to the adhesion strength. The coatings' adhesion strength of the coating is very high if compared to the data belonging to other thermal spray coatings [22].

The coatings mechanical properties as well as the coatings-substrate adhesion were further studied by employing surface scratches at continuously increasing vertical loads. The vertical loads-scratch depths curves are plotted in Fig. 11 for all the sprayed coatings.

For the Cu coating with $0.1 \mathrm{~mm}$ in thickness, the linear behavior is altered around the scratch depth of $100 \mu \mathrm{m}$ because of the indent reaching the substrate. The scratched coatings behavior is revealed by the scratch tracks after loading. These are shown in 10, for $\mathrm{Cu}$ and Ti coatings.

The deep observation of the load-depth behavior allows to identify the various critical loads (CL). Coatings are progressively damaged upon scratch and consequently some specific mechanisms can be individuated as the vertical load increases. The mechanisms are cracking, fractures and final decohesion. The observation of these features permits to 

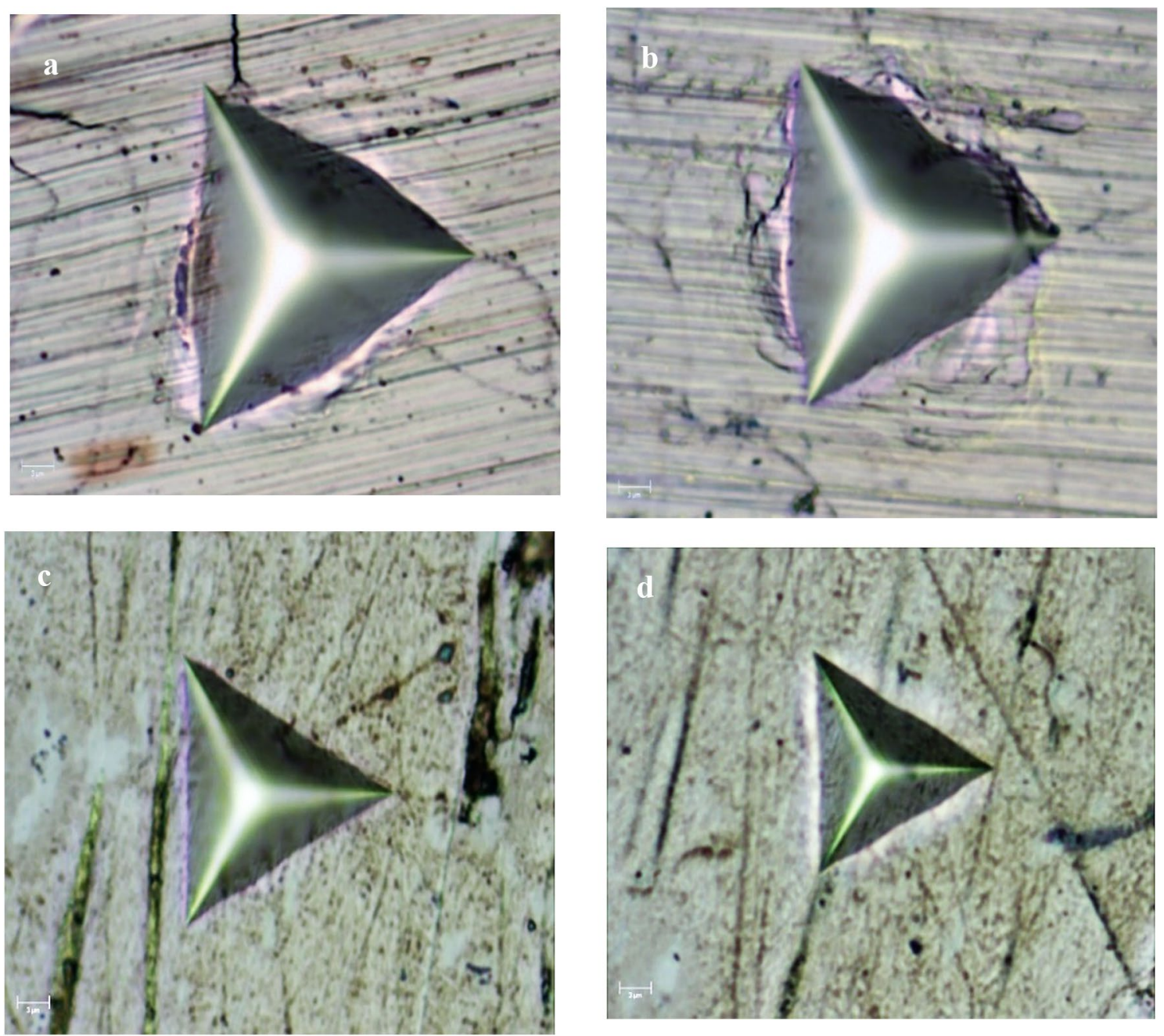

Fig. 7 Indentations aspect: (a) $\mathrm{Cu} 0.1 \mathrm{~mm}$, (b) $\mathrm{Cu} 1.0 \mathrm{~mm}$, (c) Ti $0.2 \mathrm{~mm}$, and (d) Ti $1.0 \mathrm{~mm}$ coatings
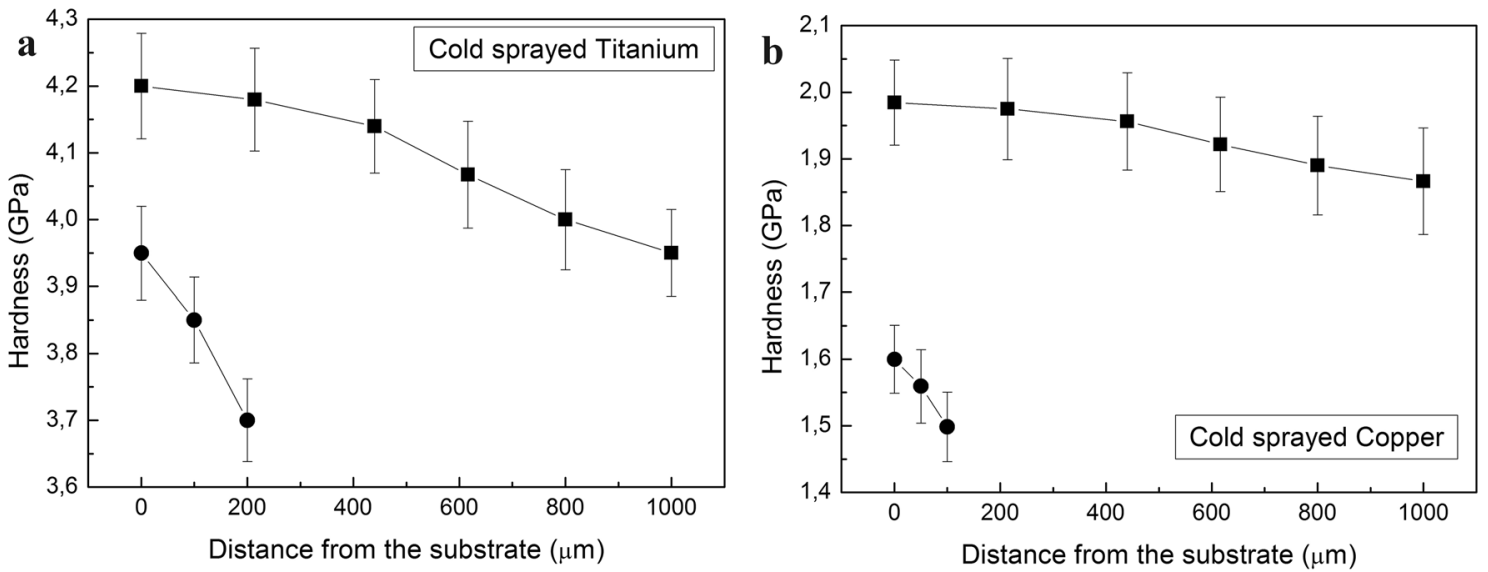

Fig. 8 Hardness variation as a function of the distance from the substrate for all the cold-sprayed coatings 

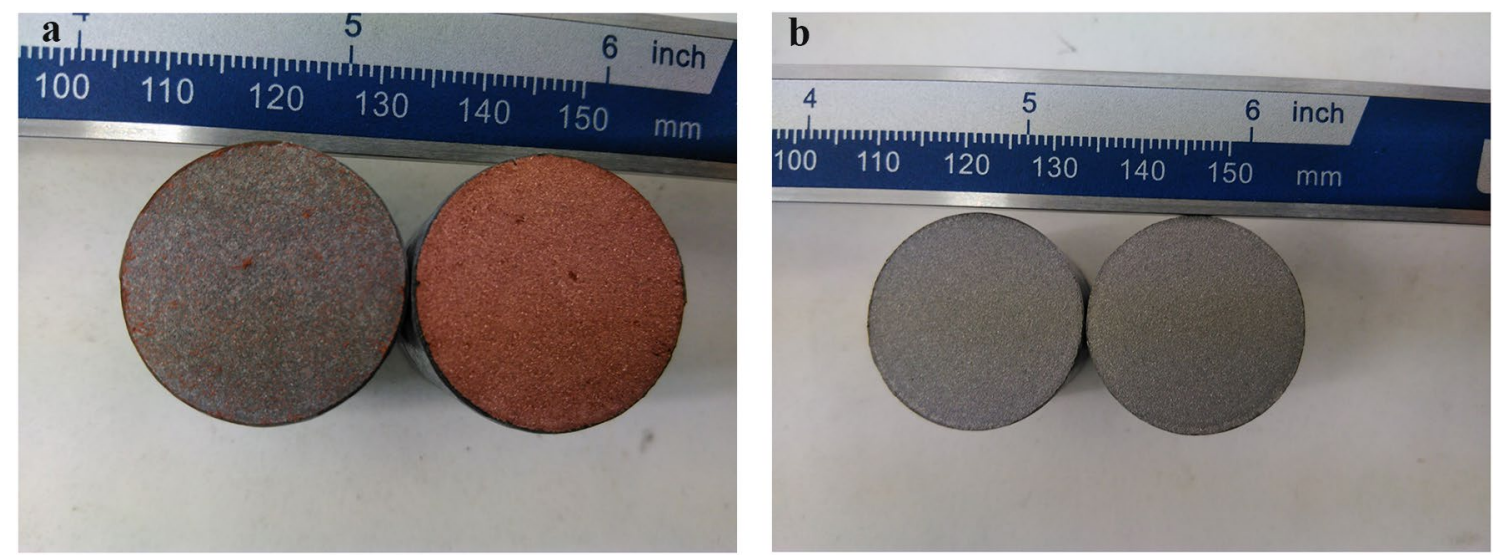

Fig. 9 Coated cylinders after tensile tests performed for adhesion measurement

identify the critical loads that produce such damaging. As the vertical load increases, stress in the coating increases by inducing specific mechanisms in the track. For the case of the studied coatings, the different damage mechanisms were identified through scanning electron microscopy observations of the tracks after scratching. As expected, the coatings show a different scratch behavior depending on the material composition and on the coating thickness. First of all, from the load-depth curves it appears how the copper coatings show a very regular curve while the titanium coatings show continuous variation revealing many microstructural modifications related to the material behavior during scratches. The most regular scratch behavior is shown by the copper coating with $1 \mathrm{~mm}$ thickness where the scratch does not show to produce damage in the unscratched material or fractures on the scratch surface. The scratch evolves through the formation of many peripheral copper flakes. Obviously, the flakes volume increases as the maximum load increases (Fig. 12b). By observing the titanium cold-sprayed coating with the same thickness $(1 \mathrm{~mm})$, they were observed many microstructural features inside the track and in the peripheral material. The occurrence of the critical loads means that the deformation mode is varying as the scratch continues at increased vertical loads. By setting a linearly increasing vertical load during scratch, a continuous series of damaging mechanisms is observed in the track. The damage mechanisms usually lead to the coating delamination [45]. The first critical load is normally associated with the initial damage mechanisms developing as a consequence of scratching. In the present case, it was individuated as the appearance of the first cracks on the scratch tracks where the compression forces of the indent are predominant with respect to the tangential forces (Fig. 13).

By comparing the cracks presence with the load-depth curve, it is possible to affirm that this first critical load is $48 \mathrm{~N}$ at $46 \mu \mathrm{m}$ penetration depth. The cracks intensity is enhanced as the vertical load is linearly increased. As the vertical load increases, higher compressive state is induced on the surface with consequent damage loading of the scratched material. The second critical load was attributed to the appearance of tongue-shaped cracks (Fig. 14).

These are due to a more complex multiaxial stress field induced in the material as the scratch proceeds. The second critical load was recorded at $100 \mathrm{~N}$ at $90 \mu \mathrm{m}$ penetration depth. The last critical load is characteristic of coldsprayed coatings; in this case the damage is transferred to the material surrounding the scratch with the increase in compressive stresses leading to particles decohesion (Fig. 15a) that becomes very remarkable at the vertical maximum load (Fig. 15b).

This behavior starts at the load of $127 \mathrm{~N}$. By comparing these features to the scratch behavior observed in the cold-sprayed titanium with a coating thickness of 0.2 $\mathrm{mm}$, the first cracks appear at a load of $50 \mathrm{~N}$, comparable with the observations of the coating with $1 \mathrm{~mm}$ thickness (Fig. 16a). The pronounced tongue-shaped cracks appear at $85 \mathrm{~N}$ (Fig. 16b), while the pronounced damage in the material surrounding the scratch with particles decohesion is observed at a vertical load of $135 \mathrm{~N}$ (Fig. 16c). The scratch track at the maximum vertical force is shown in Fig. 16d.

Now, also if the mechanical and microstructural behaviors of the two coatings appear very similar, it is believed that the coating thickness influences the scratch behavior. This is very pronounced in a very ductile material as copper. As a matter of fact, the scratch aspect of the coating with 0.1 $\mathrm{mm}$ thickness shows a very different behavior if compared to the coating with $1 \mathrm{~mm}$ thickness. In fact, in this case, small tongue cracks appear on the crack surface at a load of $80 \mathrm{~N}$ (Fig. 17a); the dimension of these cracks increases up to the maximum vertical load (Fig. 17b) revealing a larger sensibility to the increase in compressive stresses in cold-sprayed coatings with small thicknesses. 

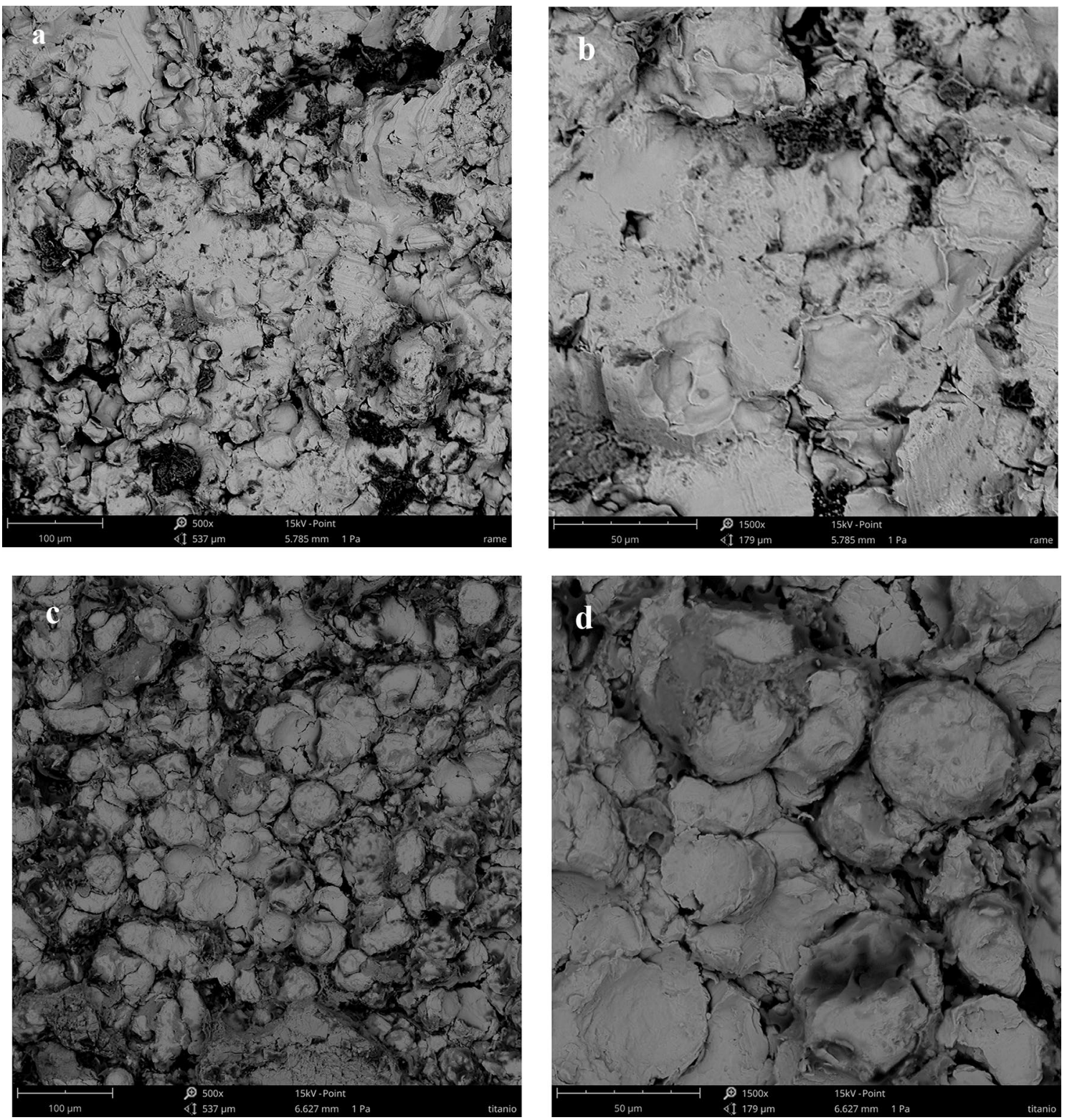

Fig. 10 Surface aspect of copper $(\mathbf{a}, \mathbf{b})$ and titanium $(\mathbf{c}, \mathbf{d})$ after tensile adhesion tests

The employed vertical loads were set to 50, 100 and 150 $\mathrm{N}$. The wear traces for $\mathrm{Cu}$ and $\mathrm{Ti}$ at $150 \mathrm{~N}$ for all the thicknesses are shown in Fig. 18.

Figure 19 shows the wear aspect and profiles. They were employed to calculate the wear damaging in terms of weight loss.

As expected, the material volume loss increases as increasing the fretting load. The weight loss is more pronounced for the thicker coatings at the same maximum load level. This was due to the increased hardening of the sprayed particles observed as the coatings thickness increases. This was shown by the lower slope of the load-weight loss curves by increasing the maximum load from $50 \mathrm{~N}$ to 100 and 150
$\mathrm{N}$. As the maximum wear force increases, the material under wear is progressively more hard as a function of the distance from the substrate. The harder material is more resistant to the wear damaging (Fig. 20).

Due to the relative movement of the contact interfaces, direction and magnitude of the force are constantly changing. This leads to the variation of the contact mechanisms and consequently to the wear behavior. The friction coefficient is the ratio between the tangential contact force during the pin slip and the normal load applied to the contact surface. Cold-sprayed coatings experience low friction at ambient temperature. The friction coefficient decreases as the maximum load increases; this confirms the described 

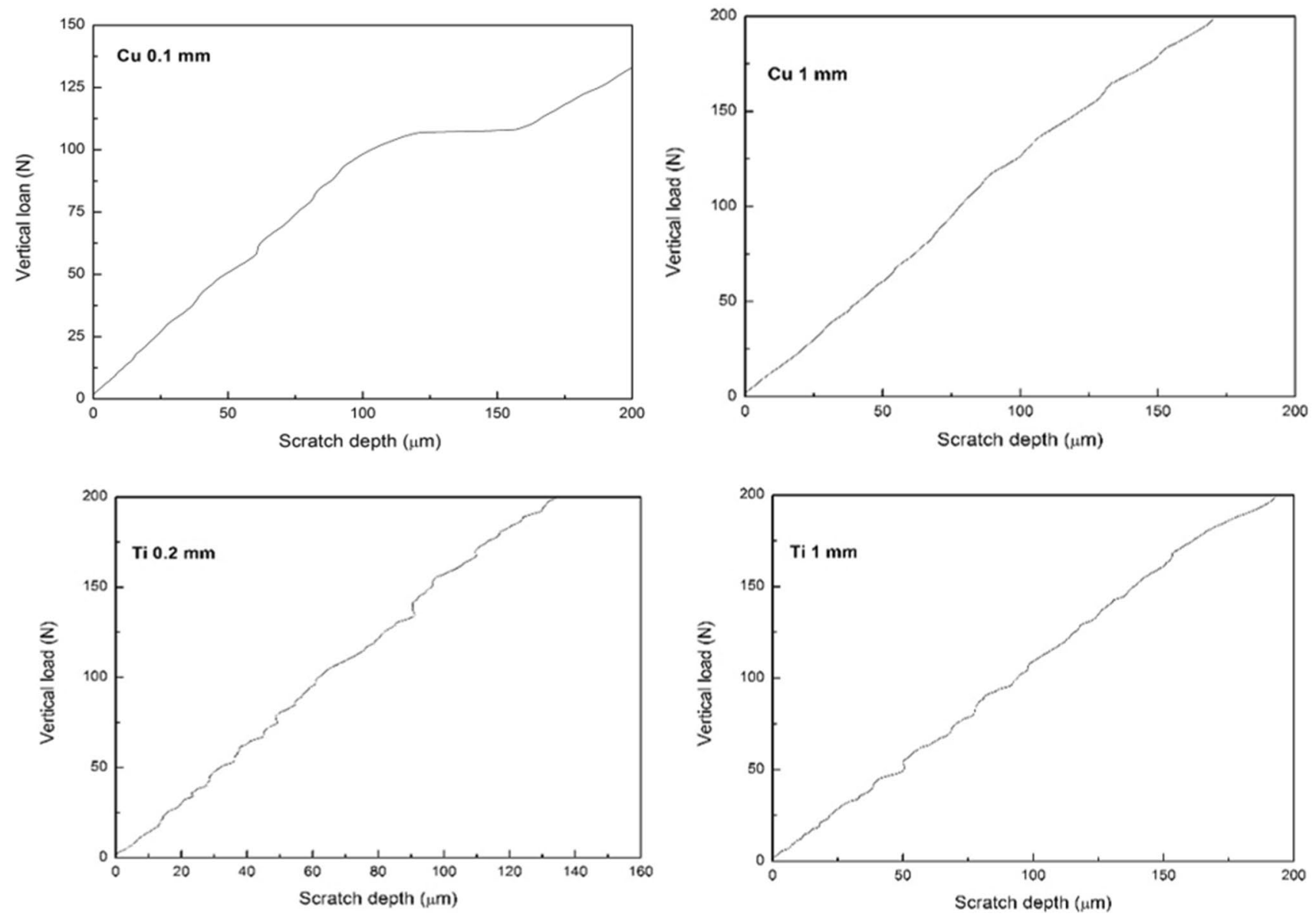

Fig. 11 Vertical load versus scratch depth. (a) Cu $0.1 \mathrm{~mm}$, (b) $\mathrm{Cu} 1.0 \mathrm{~mm}$, (c) Ti $0.2 \mathrm{~mm}$, and (d) Ti $1.0 \mathrm{~mm}$ coatings
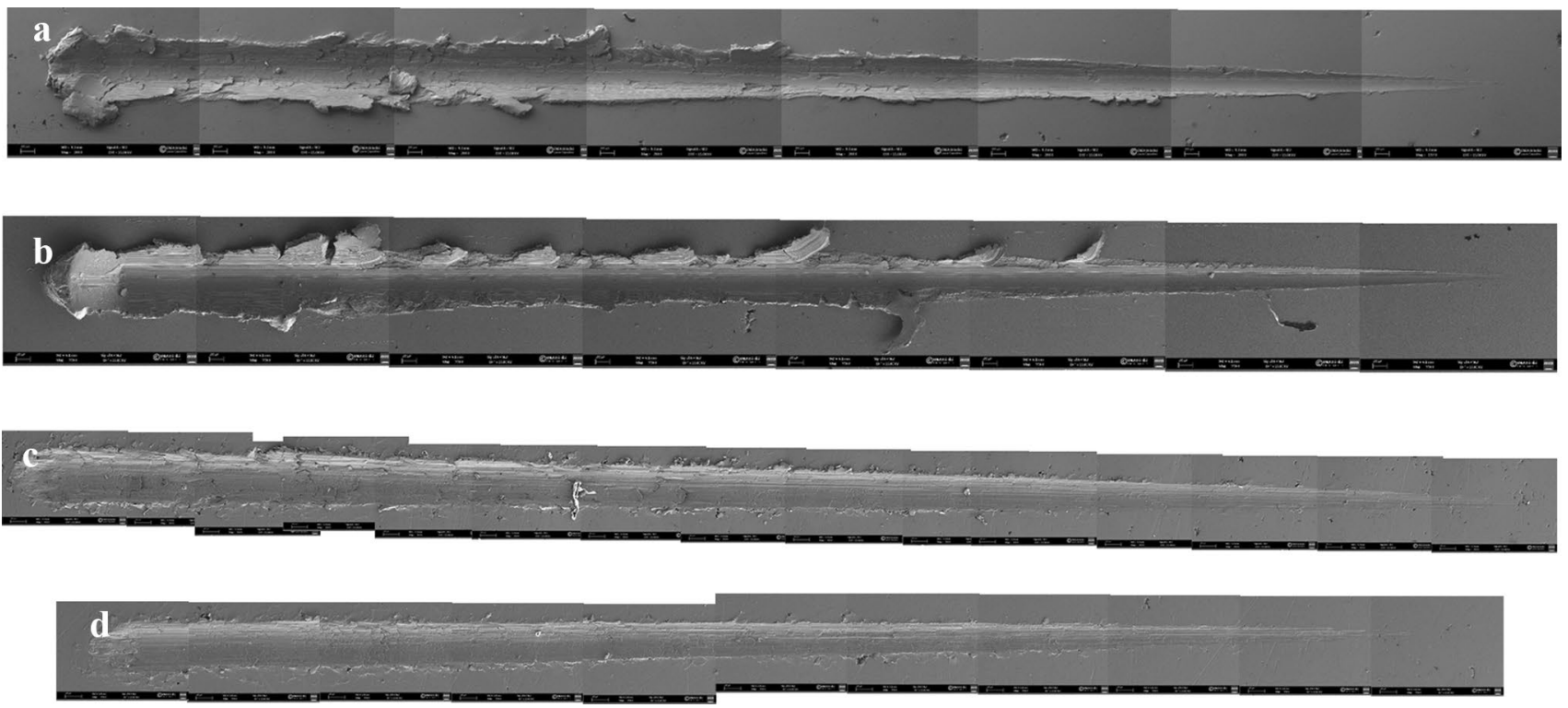

Fig. 12 Scratch tracks. (a) Cu $0.1 \mathrm{~mm}$, (b) Cu $1.0 \mathrm{~mm}$, (c) Ti $0.2 \mathrm{~mm}$, and (d) Ti $1.0 \mathrm{~mm}$ coatings 


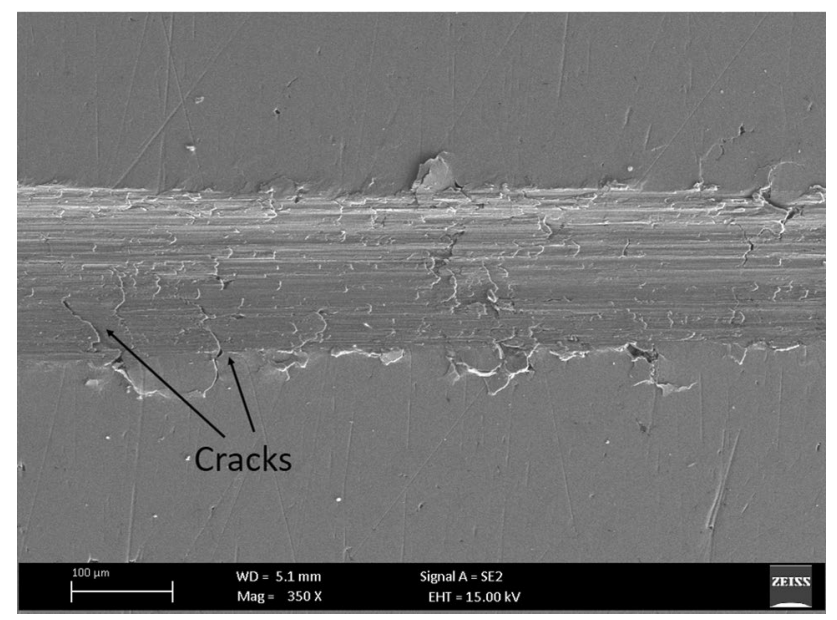

Fig. 13 First cracks appearance in the scratch track of the coldsprayed Ti with $1 \mathrm{~mm}$ thickness

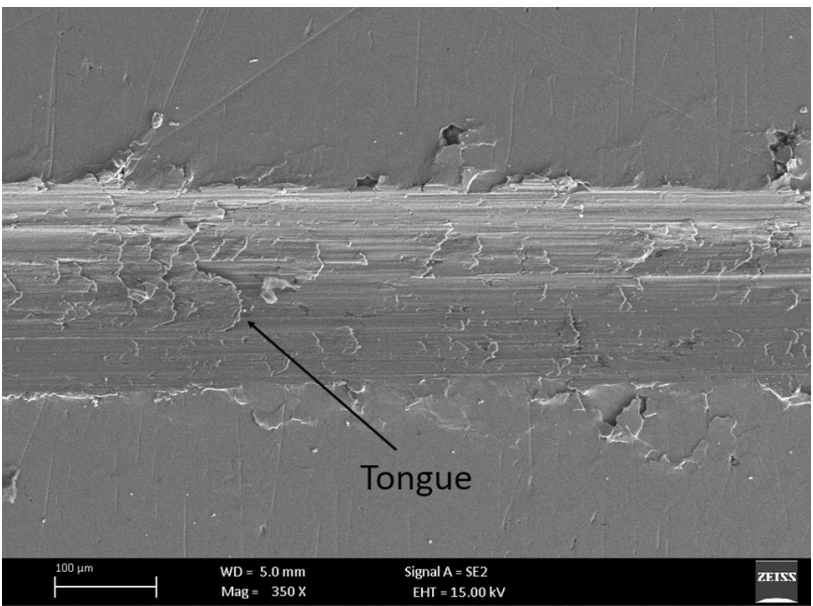

Fig. 14 Tongue shaped cracks in the scratch track of the cold-sprayed Ti with $1 \mathrm{~mm}$ thickness mechanisms due to the increase in hardness as approaching the substrate. The fretting wear of the studied coatings is plotted in Fig. 21 for the different applied maximum loads.

The effect of material hardness on the fretting wear damaging is still under debate. Recent evidences of fretting behavior of heavily hardened steels show that hardness differences reduce damaging while increased weight loss is recorded as the hardness decreases [46, 47]. Various results show the hardness behavior effect on fretting wear damaging [48]. Here, the materials hardening produced higher resistance against wearing. The hardened volume leads to friction reduction and to reduced damaging in the inner material. As the fretting material is harder, it is able to dissipate more energy being capable of resulting more stiff to wear damaging. So, the principal conclusion is that the hardness variation of cold-sprayed materials governs the weight loss and the frictional behavior of the coatings. This behavior reveals a direct relationship between the nanoindentation evolution and the fretting wear damaging.

\section{Conclusions}

The wear and fretting behavior of $\mathrm{Ti}$ and $\mathrm{Cu}$ cold-sprayed coatings with different thickness was described in the present paper. Low porosity was revealed for all the coatings; this was attributed to the optimal processing parameters selected for spraying. Nanoindentation hardness was higher for the thicker coatings because of the increases particles deformation as the particles continue to splat on the substrate and on the previously deposited particles. The coatings behavior was very different for the two materials during scratch and also for different thicknesses. The most regular scratch behavior is shown by the copper coating with $1 \mathrm{~mm}$ thickness where the scratch does not show to produce damage in the unscratched material or fractures on the scratch
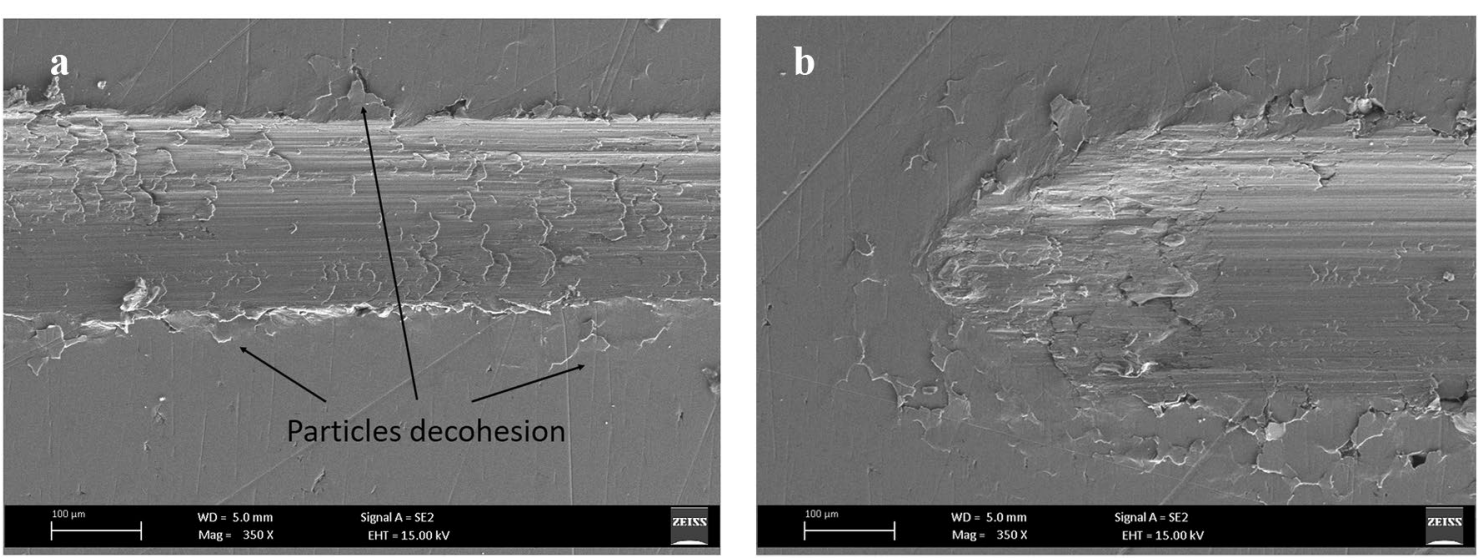

Fig. 15 Macrodamage leading to particles decohesion in the cold-sprayed Ti with $1 \mathrm{~mm}$ thickness 

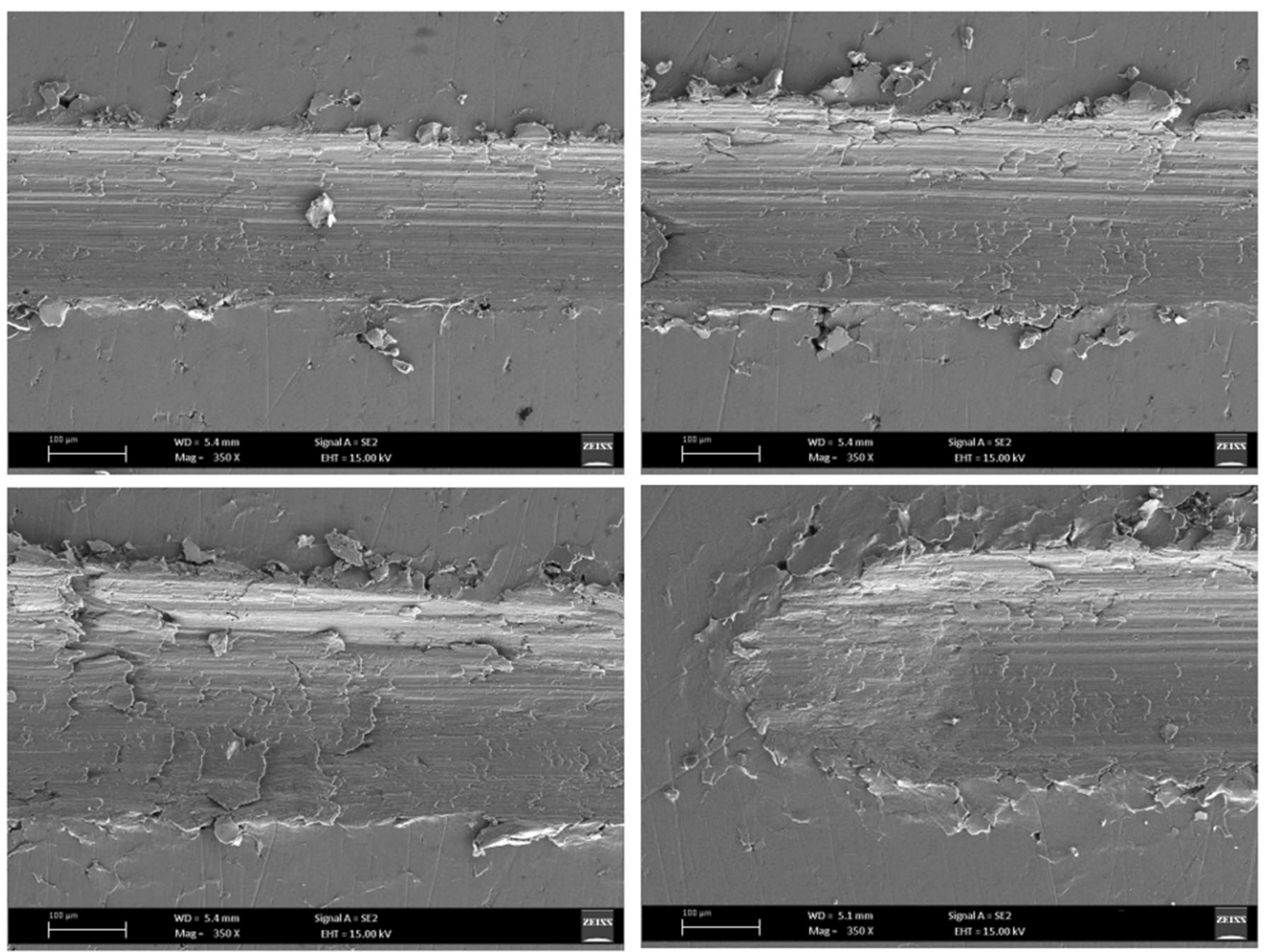

Fig. 16 Damage in the cold-sprayed Ti coating with $0.2 \mathrm{~mm}$ thickness
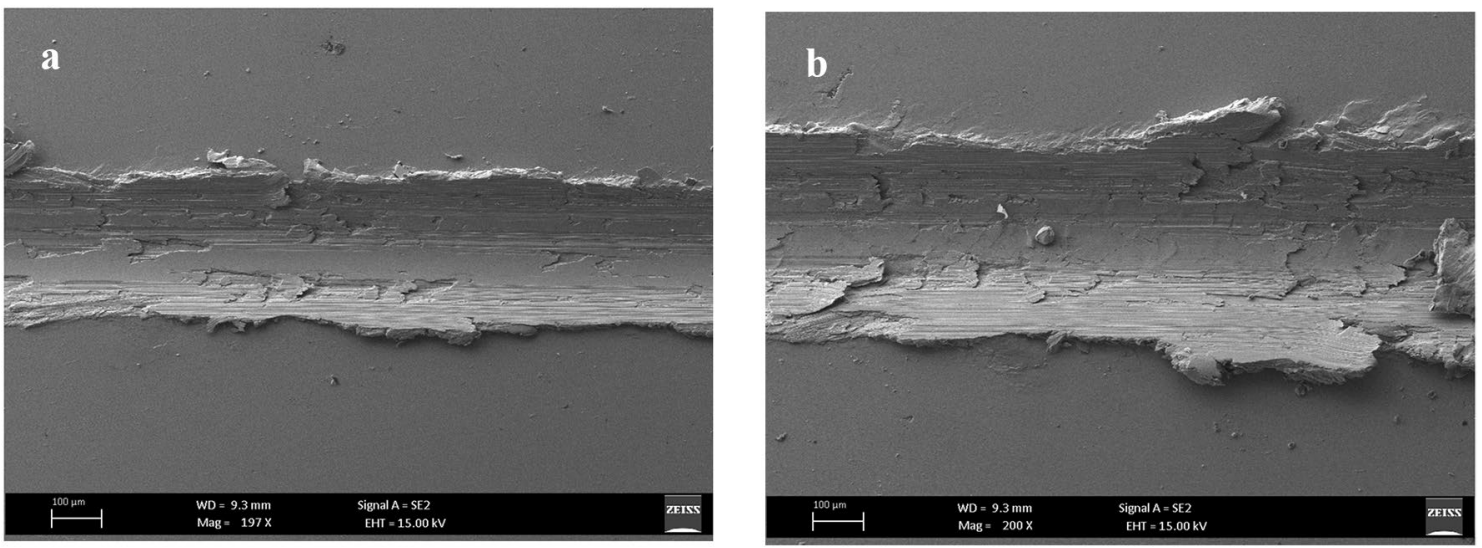

Fig. 17 Damage in the cold-sprayed Cu coating with $0.1 \mathrm{~mm}$ thickness

surface. Many damage features are revealed by titanium cold-sprayed coatings with micro-fractures and particles decohesion appearing as the vertical scratch load increases. Also the thickness influences this behavior; this was revealed by the $\mathrm{Cu}$ coatings $0.1 \mathrm{~mm}$ thick where different fractures appear in the scratch track revealing a completely different behavior with respect to the 1-mm-thick coating. The fretting results showed that the volume reduction increases for lower coatings thickness. This aspect was due to the enhanced particles severe plastic deformation observed as the coatings thickness is increased. As the maximum force increases, in fact, the fretting material is linearly harder by moving from the surface toward the substrate. This hardening induces higher resistance to wear damaging. 

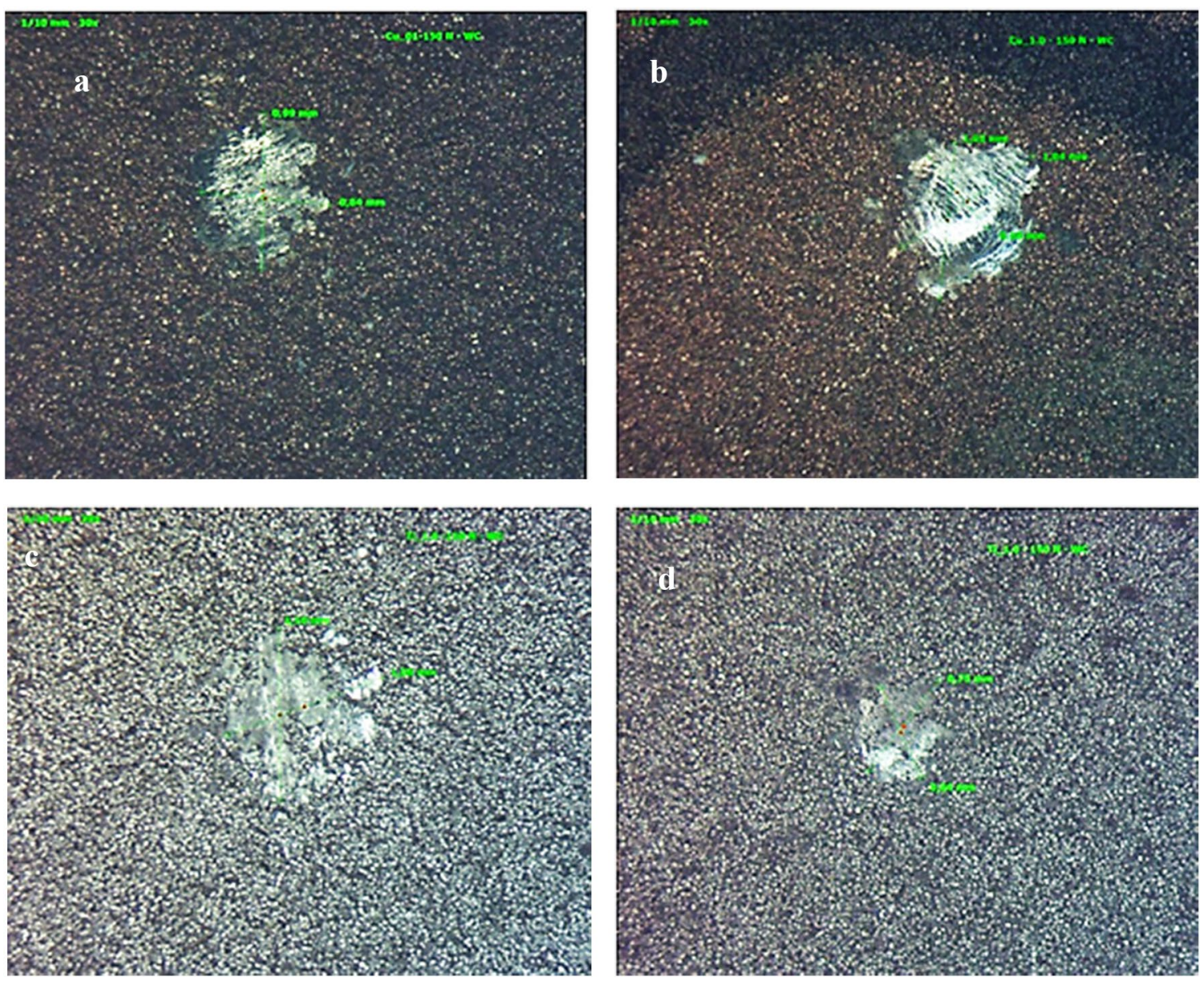

Fig. 18 Wear traces by fretting at a maximum load of $150 \mathrm{~N}$. (a, b) $\mathrm{Cu}$ and (c, d) Ti coatings 
a
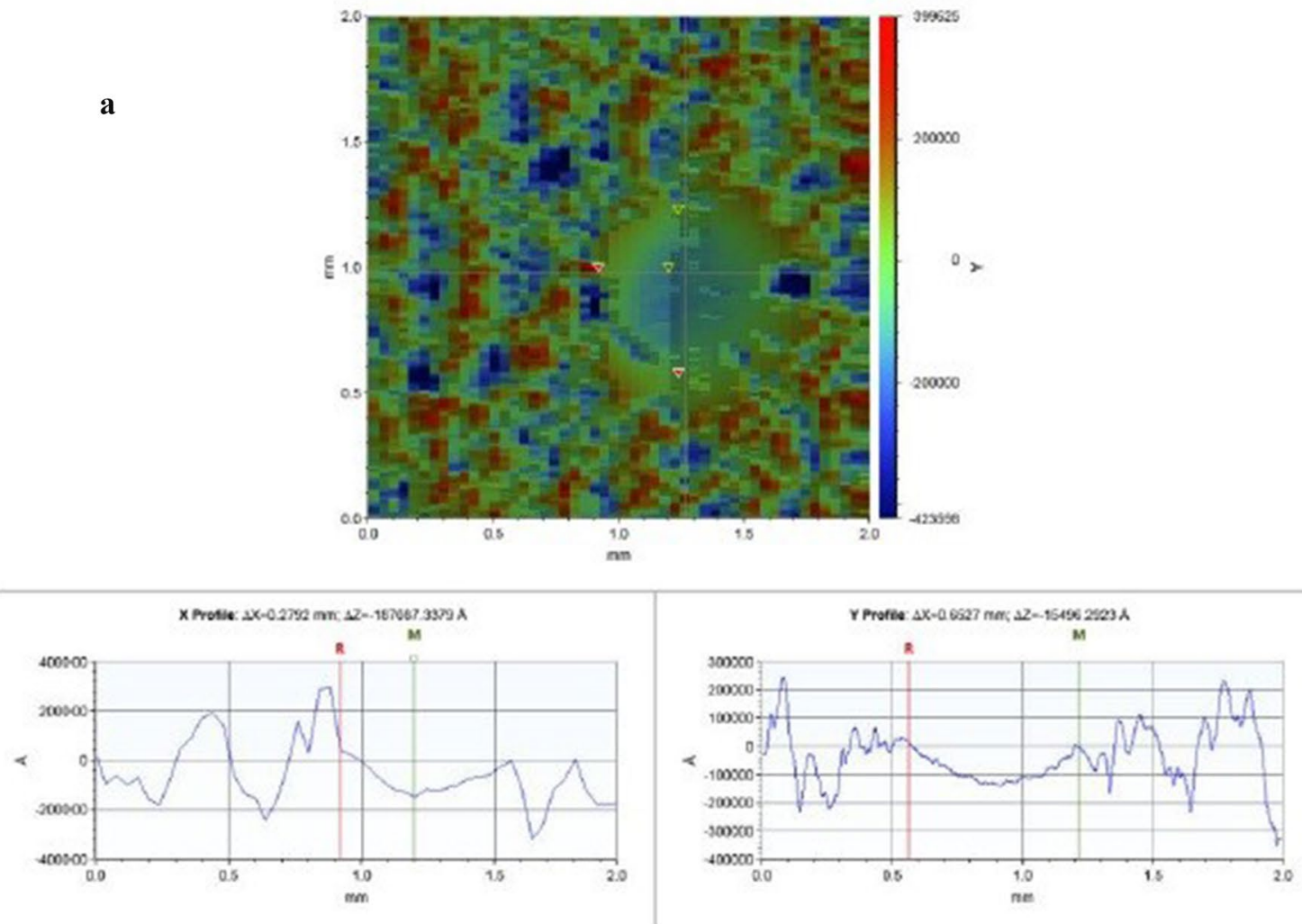

b
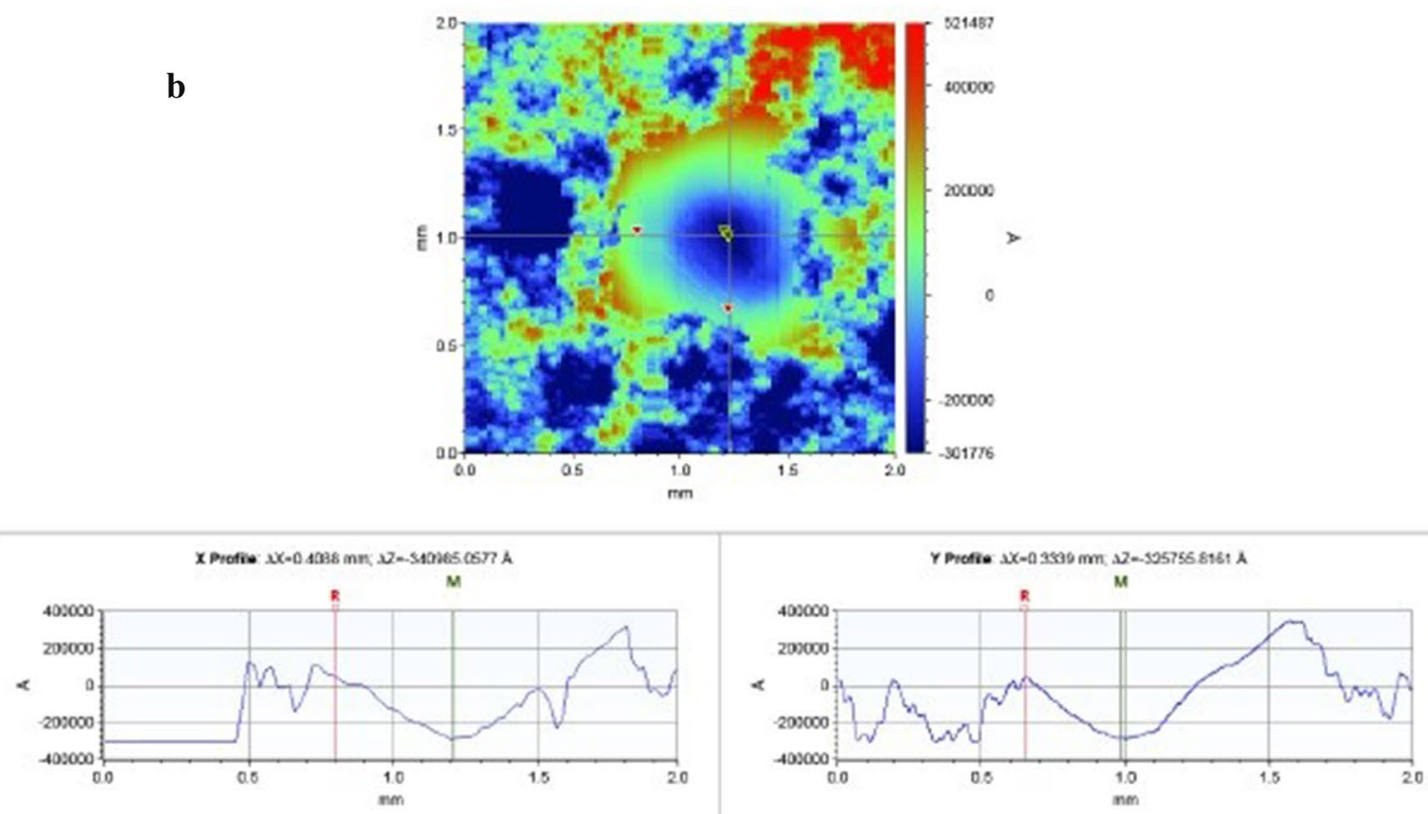

Fig. 19 Wear traces for the studied coatings after wear at a maximum load of $150 \mathrm{~N}$ 
c
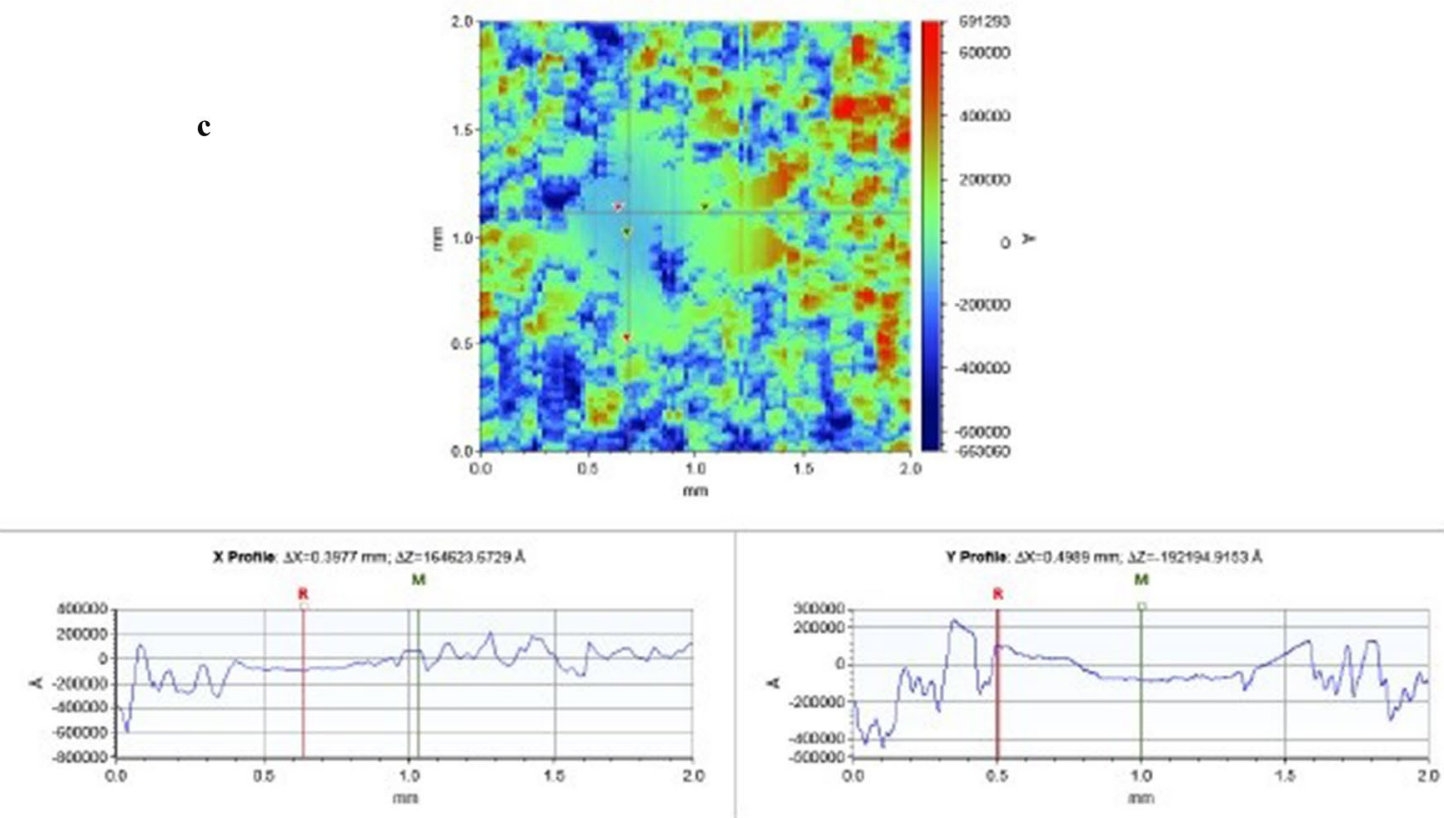

d
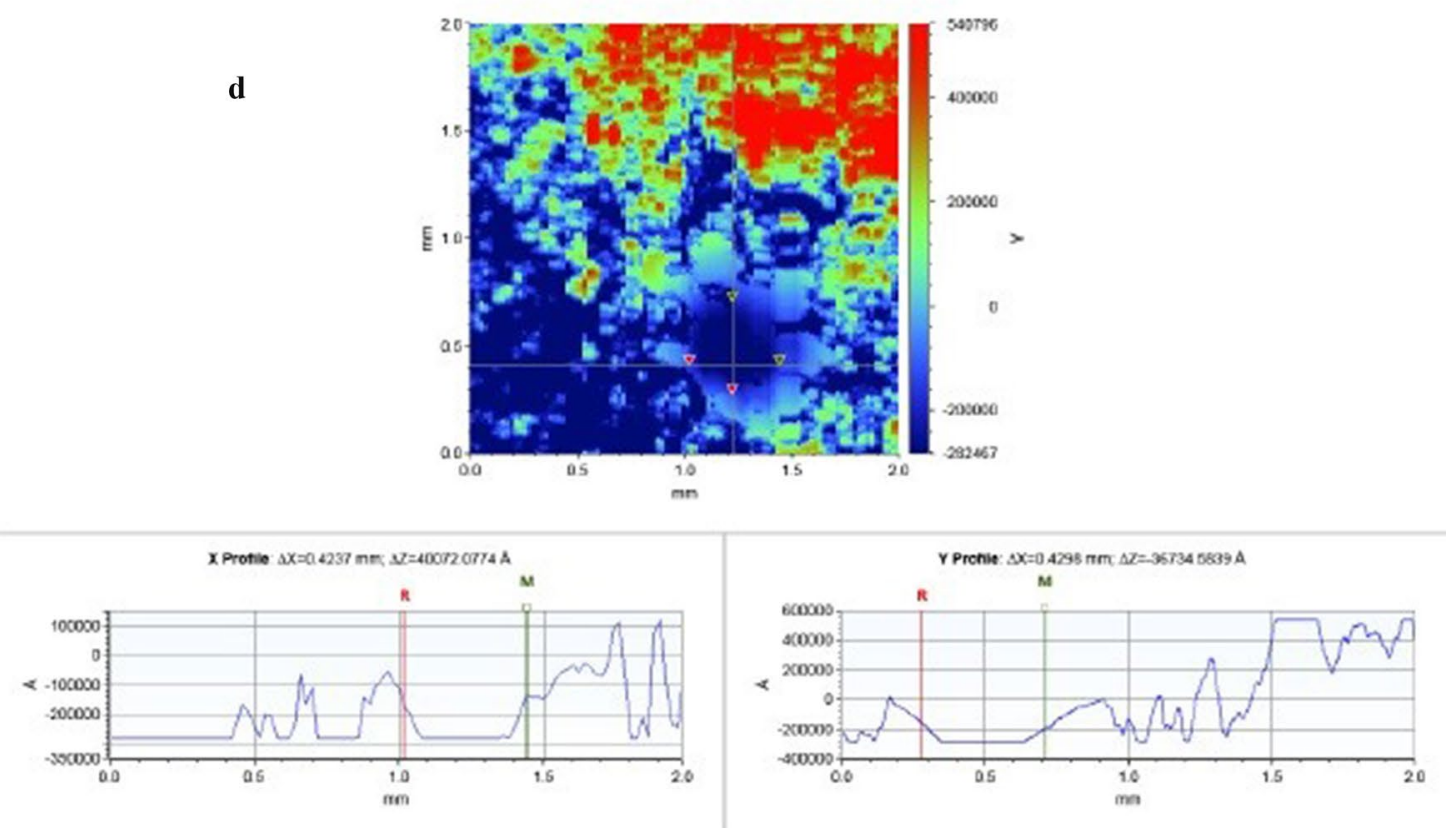

Fig. 19 (continued) 

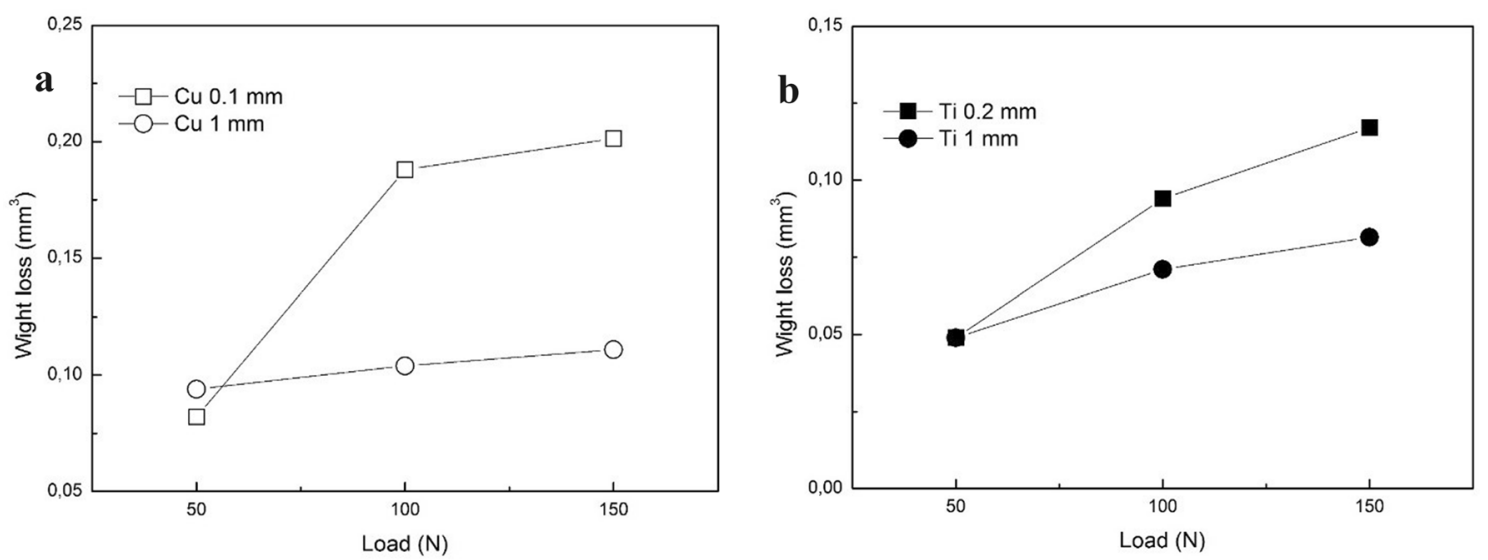

Fig. 20 Weight loss after wear testing. (a) $\mathrm{Cu}$ and (b) Ti coatings
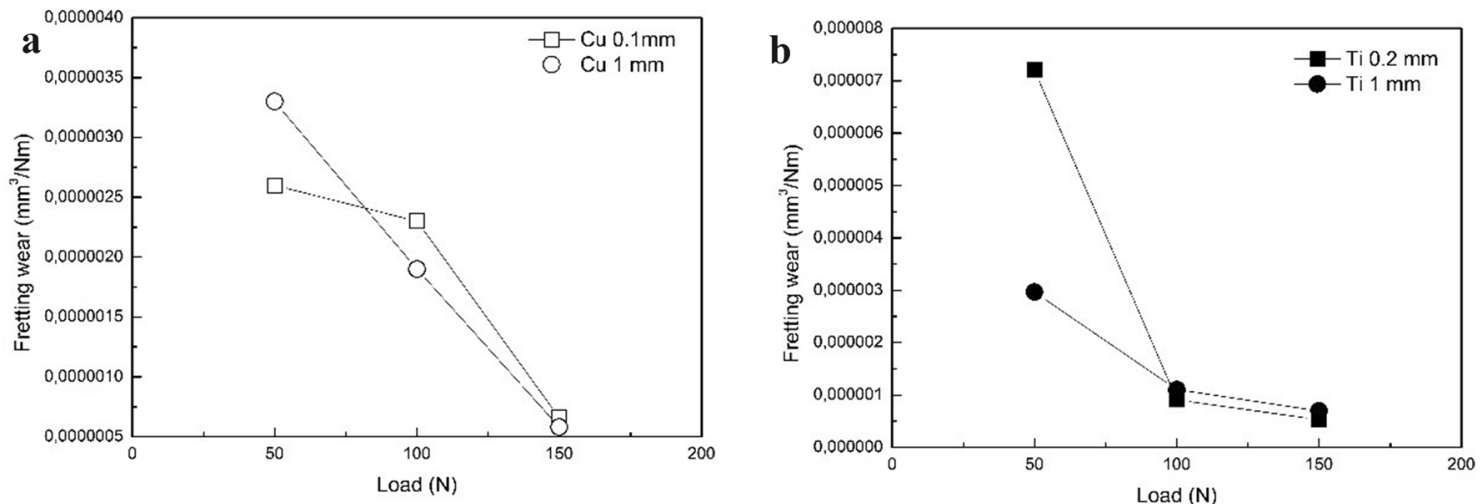

Fig. 21 Fretting wear experienced by all the coatings at different loads

Funding Open access funding provided by Università del Salento within the CRUI-CARE Agreement.

Open Access This article is licensed under a Creative Commons Attribution 4.0 International License, which permits use, sharing, adaptation, distribution and reproduction in any medium or format, as long as you give appropriate credit to the original author(s) and the source, provide a link to the Creative Commons licence, and indicate if changes were made. The images or other third party material in this article are included in the article's Creative Commons licence, unless indicated otherwise in a credit line to the material. If material is not included in the article's Creative Commons licence and your intended use is not permitted by statutory regulation or exceeds the permitted use, you will need to obtain permission directly from the copyright holder. To view a copy of this licence, visit http://creativecommons.org/licenses/by/4.0/.

\section{References}

1. S. Bagherifard, S. Monti, M.V. Zuccoli, M. Riccio, J. Kondás, M. Guagliano, Cold spray deposition for additive manufacturing of freeform structural components compared to selective laser melting. Mater. Sci. Eng. A. 721, 339-350 (2018). https://doi.org/10. 1016/j.msea.2018.02.094
2. M.E. Lynch, W. Gu, T. El-Wardany, A. Hsu, D. Viens, A. Nardi, M. Klecka, Design and topology/shape structural optimisation for additively manufactured cold sprayed components. Virtual Phys. Prototyp. 8, 213-231 (2013). https://doi.org/10.1080/17452759. 2013.837629

3. X. Wang, F. Feng, M.A. Klecka, M.D. Mordasky, J.K. Garofano, T. El-Wardany, A. Nardi, V.K. Champagne, Characterization and modeling of the bonding process in cold spray additive manufacturing. Addit. Manuf. 8, 149-162 (2015). https://doi.org/10. 1016/j.addma.2015.03.006

4. S. Yin, P. Cavaliere, B. Aldwell, R. Jenkins, H. Liao, W. Li, R. Lupoi, Cold spray additive manufacturing and repair: fundamentals and applications. Addit. Manuf. 21, 628-650 (2018). https:// doi.org/10.1016/j.addma.2018.04.017

5. A. Sova, S. Grigoriev, A. Okunkova, I. Smurov, Potential of cold gas dynamic spray as additive manufacturing technology. Int. J. Adv. Manuf. Technol. 69, 2269-2278 (2013). https://doi.org/10. 1007/s00170-013-5166-8

6. C. Chen, Y. Xie, X. Yan, S. Yin, H. Fukanuma, R. Huang, R. Zhao, J. Wang, Z. Ren, M. Liu, H. Liao, Effect of hot isostatic pressing (HIP) on microstructure and mechanical properties of Ti6Al4V alloy fabricated by cold spray additive manufacturing. Addit. Manuf. 27, 595-605 (2019). https://doi.org/10.1016/j. addma.2019.03.028 
7. S. Yin, R. Jenkins, X. Yan, R. Lupoi, Microstructure and mechanical anisotropy of additively manufactured cold spray copper deposits. Mater. Sci. Eng. A. 734, 67-76 (2018). https://doi.org/ 10.1016/j.msea.2018.07.096

8. W. Li, K. Yang, S. Yin, X. Yang, Y. Xu, R. Lupoi, Solid-state additive manufacturing and repairing by cold spraying: a review. J. Mater. Sci. Technol. 34, 440-457 (2018). https://doi.org/10. 1016/j.jmst.2017.09.015

9. S.H. Zahiri, W. Yang, M. Jahedi, Characterization of cold spray titanium supersonic jet. J. Therm. Spray Technol. 18, 110-117 (2009). https://doi.org/10.1007/s11666-008-9278-x

10. P. Cavaliere, Cold-Spray Coatings: Recent Trends and Future Perspectives (Springer, New York, 2018) https://doi.org/10.1007/ 978-3-319-67183-3

11. H. Assadi, F. Gärtner, T. Stoltenho, H. Kreye, Bonding mechanism in cold gas spraying. Acta Mater. 51, 4379-4394 (2003). https:// doi.org/10.1016/S1359-6454(03)00274-X

12. M.R. Rokni, S.R. Nutt, C.A. Widener, V.K. Champagne, R.H. Hrabe, Review of relationship between particle deformation, coating microstructure, and properties in high-pressure cold spray. J. Therm. Spray Technol. 26, 1308-1355 (2017). https://doi.org/10. 1007/s11666-017-0575-0

13. A. Silvello, P.D. Cavaliere, V. Albaladejo, A. Martos, S. Dosta, I.G. Cano, Powder properties and processing conditions affecting cold spray deposition. Coatings. 10(2), 91 (2020). https://doi.org/ 10.3390/coatings 10020091

14. P. Cavaliere, A. Silvello, Processing conditions affecting residual stresses and fatigue properties of cold spray deposits. Int. J. Adv. Manuf. Technol. 81(9-12), 1857-1862 (2015). https://doi.org/10. 1007/s00170-015-7365-y

15. Y. Xie, M.-P. Planche, R. Raoelison, H. Liao, X. Suo, P.J. Hervé, Effect of substrate preheating on adhesive strength of SS316L cold spray coatings. J. Therm. Spray Technol. 25, 123-130 (2016). https://doi.org/10.1007/s11666-015-0312-5

16. K. Kim, M. Watanabe, S. Kuroda, Bonding mechanisms of thermally softened metallic powder particles and substrates impacted at high velocity. Surf. Coat. Technol. 204, 2175-2180 (2010). https://doi.org/10.1016/j.surfcoat.2009.12.001

17. M. Hassani-Gangaraj, D. Veysset, V.K. Champagne, K.A. Nelson, C.A. Schuh, Adiabatic shear instability is not necessary for adhesion in cold spray. Acta Mater. 158, 430-439 (2018). https://doi. org/10.1016/j.actamat.2018.07.065

18. P. Cavaliere, A. Silvello, Finite element analyses of pure Ni cold spray particles impact related to coating crack behaviour. Surf. Eng. 34(5), 361-368 (2018). https://doi.org/10.1080/02670844. 2017.1287555

19. P. Cavaliere, A. Perrone, A. Silvello, Pure cobalt cold spray nanostructured coatings. J. Therm. Spray Technol. 25(6), 1168-1176 (2016). https://doi.org/10.1007/s11666-016-0434-4

20. P. Cavaliere, A. Perrone, A. Silvello, Crystallization evolution of cold sprayed pure Ni coatings. J. Therm. Spray Technol. 25(6), 1158-1167 (2016). https://doi.org/10.1007/s11666-016-0430-8

21. S. Yin, X. Wang, X. Suo, H. Liao, Z. Guo, W. Li, C. Coddet, Deposition behavior of thermally softened copper particles in cold spraying. Acta Mater. 61, 5105-5118 (2013). https://doi.org/10. 1016/j.actamat.2013.04.041

22. P. Cavaliere, A. Silvello, N. Cinca, H. Canales, S. Dosta, I. Garcia Cano, J.M. Guilemany, Microstructural and fatigue behavior of Cold Sprayed Ni-based superalloys coatings. Surf. Coat. Technol. 324, 390-402 (2017). https://doi.org/10.1016/j.surfcoat.2017.06. 006

23. N. Cinca, C.R.C. Lima, J.M. Guilemany, An overview of intermetallics research and application: status of thermal spray coatings. J. Mater. Res. Technol. 2, 75-86 (2013). https://doi.org/10.1016/j. jmrt.2013.03.013
24. R.R. Boyer, An overview on the use of titanium in the aerospace industry. Mater. Sci. Eng. A. 213, 103-114 (1996). https://doi.org/ 10.1016/0921-5093(96)10233-1

25. J. Ajaja, D. Goldbaum, R.R. Chromik, Characterization of Ti cold spray coatings by indentation methods. Acta Astronaut. 69, 923-928 (2011). https://doi.org/10.1016/j.actaastro.2011.06.012

26. M. Geetha, A.K. Singh, R. Asokamani, A.K. Gogia, Ti based biomaterials, the ultimate choice for orthopaedic implants-a review. Prog. Mater. Sci. 54, 397-425 (2009). https://doi.org/10.1016/j. pmatsci.2008.06.004

27. S.M. Hassani-Gangaraj, A. Moridi, M. Guagliano, Critical review of corrosion protection by cold spray coatings. Surf. Eng. 31, 803-815 (2015). https://doi.org/10.1179/1743294415Y.00000 00018

28. J. Huang, X. Yan, C. Chang, Y. Xie, W. Ma, R. Huang, R. Zhao, S. Li, M. Liu, H. Liao, Pure copper components fabricated by cold spray (CS) and selective laser melting (SLM) technology. Surf. Coat. Technol. 395, 125936 (2020). https://doi.org/10.1016/j.surfc oat.2020.125936

29. C. Silbernagel, L. Gargalis, I. Ashcroft, R. Hague, M. Galea, P. Dickens, Electrical resistivity of pure copper processed by medium-powered laser powder bed fusion additive manufacturing for use in electromagnetic applications. Addit. Manuf. 29, 100831 (2019). https://doi.org/10.1016/j.addma.2019.100831

30. E. Napieralska-Juszczak, K. Komeza, F. Morganti, J.K. Sykulski, G. Vega, Y. Zeroukhi, Measurement of contact resistance for copper and aluminium conductors. Int. J. Appl. Electromagn. Mech. 53, 617-629 (2017). https://doi.org/10.3233/JAE-160025

31. S. Shah, K.K. Kumar, Experimental study \& heat transfer analysis on copper spiral heat exchanger using water based $\mathrm{SiO}_{2}$ nanofluid as coolant. World J. Nano Sci. Eng. 8, 57-68 (2018). https://doi. org/10.4236/wjnse.2018.84004

32. Astarita, A., Rubino, F., Carlone, P., Ruggiero, A., Leone, C., Genna, S., Merola, M., Squillace, A.: On the improvement of AA2024 wear properties through the deposition of a cold-sprayed titanium coating, Metals (Basel) 6 (2016). https://doi.org/10.3390/ met6080185.

33. Z. Jia, Y. Wang, J. Ji, X. Sun, Fretting wear properties of thermally deformed Inconel 625 alloy. Trans. Ind. Inst. Met. (2020). https:// doi.org/10.1007/s12666-020-02085-6

34. S.R. Soria, A. Tolley, A. Yawny, Characterization of damage and triboparticles resulting from fretting of Incoloy 800 steam generator tubes against different materials. Wear. 390-391, 198-208 (2017). https://doi.org/10.1016/j.wear.2017.07.022

35. P. Sirventa, M.A. Garrido, S. Lozano-Perez, P. Poza, Oscillating and unidirectional sliding wear behaviour of cold sprayed Ti-6Al$4 \mathrm{~V}$ coating on Ti-6Al-4V substrate. Surf. Coat. Technol. 382, 125152 (2020). https://doi.org/10.1016/j.surfcoat.2019.125152

36. N.W. Khun, A.W.Y. Tan, E. Liu, Mechanical and tribological properties of coldsprayed Ti coatings on Ti-6Al-4V substrates. J. Therm. Spray Technol. 25, 715-724 (2016). https://doi.org/10. 1007/s11666-016-0396-6

37. P. Cavaliere, Mechanical properties of nanocrystalline metals and alloys studied via multi-step nanoindentation and finite element calculations. Mater. Sci. Eng. A. 512, 1-9 (2009). https://doi.org/ 10.1016/j.msea.2009.03.008

38. Y. Chen, S.R. Bakshi, A. Agarwal, Correlation between nanoindentation and nanoscratch properties of carbon nanotube reinforced aluminum composite coatings. Surf. Coat. Technol. 204, 2709-2715 (2010). https://doi.org/10.1016/j.surfcoat.2010.02.024

39. J.-D. Kwon, D.-K. Park, S.-W. Woo, D.-H. Yoon, I. Chung, A study on fretting fatigue life for the Inconel alloy 600 at high temperature. Nuclear Eng. Des. 240, 2521-2527 (2010). https:// doi.org/10.1016/j.nucengdes.2010.05.013 
40. P.D. Cavaliere, A. Rizzo, D. Valerini, L. Capodieci, Wear and fretting behavior of cold sprayed IN625 superalloy. Metals. 49, 1-13 (2021). https://doi.org/10.3390/met11010049

41. T. Hussain, Cold spraying of titanium: a review of bonding mechanisms, microstructure and properties. Key Eng. Mater. 533, 53-90 (2012). https://doi.org/10.4028/www.scientific.net/kem.533.53

42. A. Silvello, P. Cavaliere, A. Rizzo, D. Valerini, S. Dosta, I. Garcia Cano, Fatigue bending behavior of cold-sprayed nickel-based superalloy coatings. J. Therm. Spray Technol. 28(5), 930-938 (2019). https://doi.org/10.1007/s11666-019-00865-1

43. P.D. Eason, J.A. Fewkes, S.C. Kennett, T.J. Eden, K. Tello, M.J. Kaufman, M. Tiryakioglu, On the characterization of bulk copper produced by cold gas dynamic spray processing in as fabricated and annealed conditions. Mater. Sci. Eng. A. 528, 8174-8178 (2011). https://doi.org/10.1016/j.msea.2011.07.012

44. A. Leyland, A. Matthews, On the significance of the H/E ratio in wear control: a nanocomposite coating approach to optimized tribological behavior. Wear. 246, 1-11 (2000). https://doi.org/10. 1016/S0043-1648(00)00488-9
45. R. Valentini, P. Cavaliere, D. Valerini, Nanoindentation and scratch behaviour of Ni-P electroless coatings. Tribol. Mater. Surf. Interfaces. 14(1), 22-32 (2020). https://doi.org/10.1080/ 17515831.2019.1665787

46. K.G. Budinski, Effect of hardness differential on metal-to-metal fretting damage. Wear. 301, 501-507 (2013). https://doi.org/10. 1016/j.wear.2013.01.003

47. J. Li, Y. Lu, H. Zhang, L. Xin, Effect of grain size and hardness on fretting wear behavior of Inconel 600 alloys. Tribol. Int. 81, 215-222 (2015). https://doi.org/10.1016/j.triboint.2014.08.005

48. L. Xin, B.B. Yang, Z.H. Wang, J. Li, Y.H. Lu, T. Shoji, Microstructural evolution of subsurface on Inconel 690TT alloy subjected to fretting wear at elevated temperature. Mater. Des. 104, 152-161 (2016). https://doi.org/10.1016/j.matdes.2016.05.030

Publisher's Note Springer Nature remains neutral with regard to jurisdictional claims in published maps and institutional affiliations. 